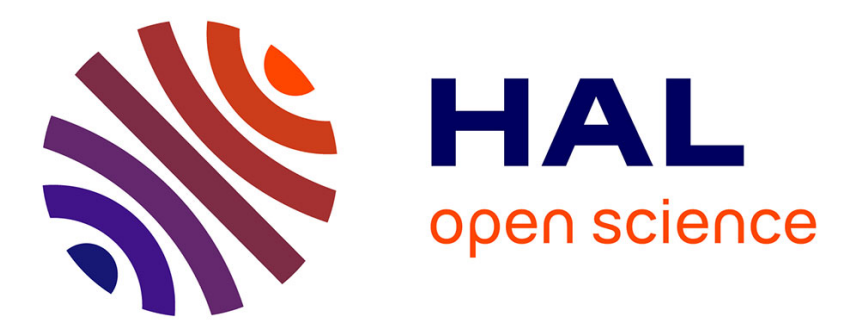

\title{
Access to (Hetero) arylated Selenophenes via Palladium-catalysed Stille, Negishi or Suzuki Couplings or C-H Bond Functionalization Reaction
}

Aymen Skhiri, Ridha Ben Salem, Jean-François Soulé, Henri Doucet

\section{- To cite this version:}

Aymen Skhiri, Ridha Ben Salem, Jean-François Soulé, Henri Doucet. Access to (Hetero) arylated Selenophenes via Palladium-catalysed Stille, Negishi or Suzuki Couplings or C-H Bond Functionalization Reaction. ChemCatChem, 2017, 9 (15), pp.2895-2913. 10.1002/cctc.201700256 . hal-01578539

HAL Id: hal-01578539

https://hal-univ-rennes1.archives-ouvertes.fr/hal-01578539

Submitted on 29 Aug 2017

HAL is a multi-disciplinary open access archive for the deposit and dissemination of scientific research documents, whether they are published or not. The documents may come from teaching and research institutions in France or abroad, or from public or private research centers.
L'archive ouverte pluridisciplinaire $\mathbf{H A L}$, est destinée au dépôt et à la diffusion de documents scientifiques de niveau recherche, publiés ou non, émanant des établissements d'enseignement et de recherche français ou étrangers, des laboratoires publics ou privés. 


\section{Access to (hetero)arylated selenophenes via palladium-catalysed Stille, Negishi or}

\section{Suzuki couplings or $\mathbf{C}-\mathbf{H}$ bond functionalization reaction}

Aymen Skhiri, ${ }^{[a, b]}$ Ridha Ben Salem, ${ }^{[b]}$ Jean-François Soulé, ${ }^{[a] *}$ Henri Doucet ${ }^{[a] *}$

[a] A. Skhiri, Dr. J-F. Soulé, Dr. H. Doucet

Institut des Sciences Chimiques de Rennes, UMR 6226 CNRS-Université de Rennes 1

"Organométalliques, Matériaux et Catalyse", Campus de Beaulieu, 35042 Rennes, France.

Tel: +(33) 0223233206; +(33) 0223236384.

E-mail: jean-francois.soule@univ-rennes1.fr, henri.doucet@univ-rennes1.fr

[b] A. Skhiri, Prof. R. Ben Salem

Laboratoire de Chimie Organique Physique (UR 11ES74) Université de Sfax, Faculté des

Sciences de Sfax, Route de la Soukra km 4, 3038 Sfax, Tunisie.

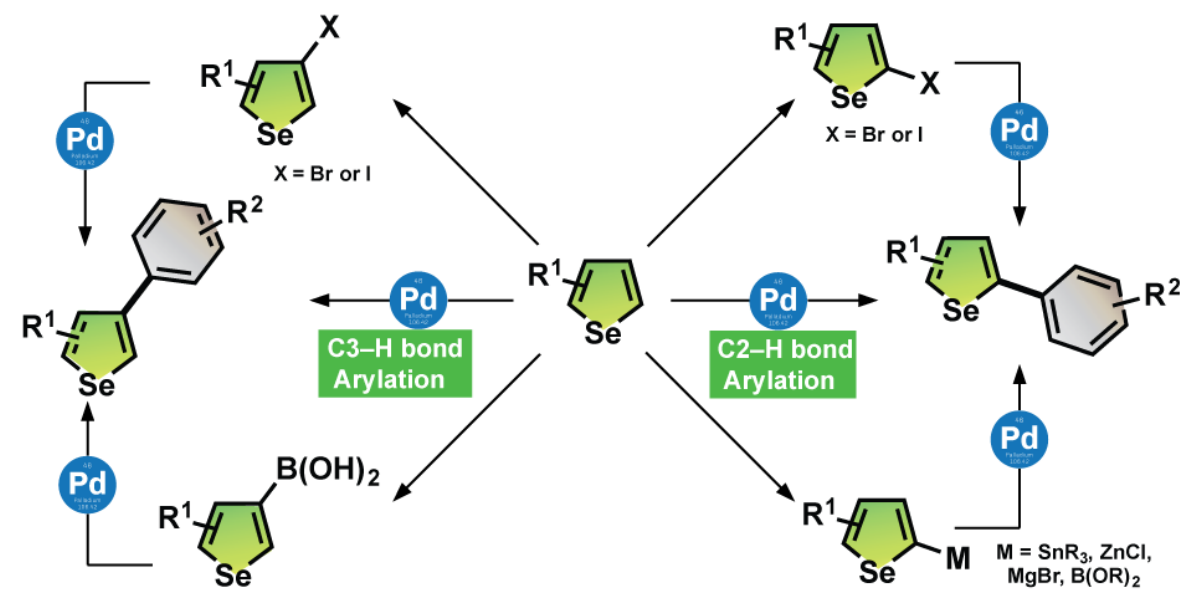

Abstract: (Hetero)aryl-substituted selenophenes exhibit important physical properties especially for optoelectronics. Palladium-catalysed coupling reactions currently represent the most efficient methods to prepare such (hetero)arylated selenophene derivatives. Initially, Stille coupling was the most efficient reaction for the synthesis of these compounds; however, over the last decade, Suzuki coupling is the most commonly employed coupling reaction. Recently, Pd-catalysed arylation via the C-H bond activation of selenophenes has proved to be a very convenient alternative method for the preparation of several arylated selenophenes as there is no need to prepare organometallic derivatives. In this review, the progress and substrate scope in the synthesis of both $\mathrm{C} 2-$ and $\mathrm{C} 3$-arylated selenophenes via Pdcatalysis are summarized. 


\section{Introduction}

\section{C2-arylation of selenophenes}

\subsection{C2-arylation via Stille coupling}

\subsection{C2-arylation via Negishi or Kumada coupling}

\subsection{C2-arylation via Suzuki coupling}

\subsection{C2-arylation via $\mathrm{C}-\mathrm{H}$ bond functionalization}

\section{C3-arylation of selenophenes}

\subsection{C3-arylation via Stille coupling}

\subsection{C3-arylation via Negishi coupling}

\subsection{C3-arylation via Suzuki coupling}

\subsection{C3-arylation via C-H bond functionalization}

\section{Conclusions and perspectives}

\section{References}

\section{Introduction}

(Poly)aryl-containing selenophenes represents a class of molecules which exhibit important physical properties, especially for the preparation of artificial photosynthetic systems for solar energy conversion. ${ }^{[1]}$ Some copolymers containing selenophene and thiophene units exhibit broad optical absorption properties. $^{[1 \mathrm{a}]}$ Benzotriazole-based dipolar dyes containing selenophene have been recently developed as sensitizers for dye-sensitized solar cells. ${ }^{[1 b]}$ Small molecules using selenophene as electron linker for application in solar cells have also been described. ${ }^{[1 \mathrm{c}]}$ Selenophene units have also been included in tetracationic cyclophanes for the preparation of photosynthetic systems. ${ }^{[1 \mathrm{~d}]}$ Moreover, the recent high number of patent publications concerning selenophene derivatives highlights the importance of these motifs in the search for new materials.

The most classical methods for the synthesis of (hetero)arylated selenophenes are through the use of transition-metal mediated reactions. ${ }^{[2]}$ Among these methods, currently the Pd-catalysed Stille, Negishi, Kumada and especially Suzuki-Miyaura couplings represent the most important reactions. They allow the preparation of both C2- and C3-(hetero)arylated selenophenes and also poly(hetero)arylated selenophenes. However, they require the preliminary preparation of an organometallic (or boron) derivative of an (hetero)aryl derivative, and provide an organometallic salt $(\mathrm{MX})$ as by-product. In recent years, a few examples of Pd-catalysed C2- and C3-functionalisations of 
selenophenes via $\mathrm{C}-\mathrm{H}$ bond activation have also been reported providing a straightforward method for the synthesis of arylated selenophenes.

The Pd-catalysed arylation of heteroaromatics has been covered in the last years by several relevant reviews. ${ }^{[3]}$ However, to the best of our knowledge, there is no review focussing on the palladium-catalysed arylation of selenophenes. In this review, we summarize the developments concerning intermolecular palladium-catalysed arylations of selenophenes. In the first part, (hetero)arylations at C2- and/or C5-positions of selenophenes via Stille, Negishi, Kumada, Suzuki couplings and also via $\mathrm{C}-\mathrm{H}$ functionalisation shall be reviewed. In the second part, the Pd-catalysed C3and/or C4-(hetero)arylations of selenophenes will be discussed. The remaining challenges in the field are evoked to conclude.

\section{C2-arylation of selenophenes}

From selenophene, which is a commercially available compound, 2-bromoselenophene and 2,5dibromoselenophene can be regioselectively obtained by reaction with $N$-bromosuccinimide (NBS); whereas, no formation of 3-bromoselenophene was observed. ${ }^{[4 \mathrm{c}, \mathrm{d}]}$ This is currently the most common route for access to bromo-substituted selenophenes. Bromination reactions at C5-position of 2selenophenecarboxaldehyde and 2-acetylselenophene in the presence of bromine have also been reported. ${ }^{[4 \mathrm{~b}]}$ The reaction of selenophene with butyllithium followed by addition of iodine gave 2iodoselenophene or 2,5-diiodoselenophene (Fig. 1, left). ${ }^{[4 c]}$ The deprotonation of selenophenes by butyllithium followed by addition of trialkyltin chlorides provides the 2(trialkylstannyl)selenophenes. ${ }^{[4 a]}$ Treatment of selenophene by butyllithium, then by a boronate affords the 2-thienylboronates (Fig. 1, right). ${ }^{[4 \mathrm{~d}]}$ From these functionalized selenophenes, several examples of Stille or Suzuki couplings have been described. 


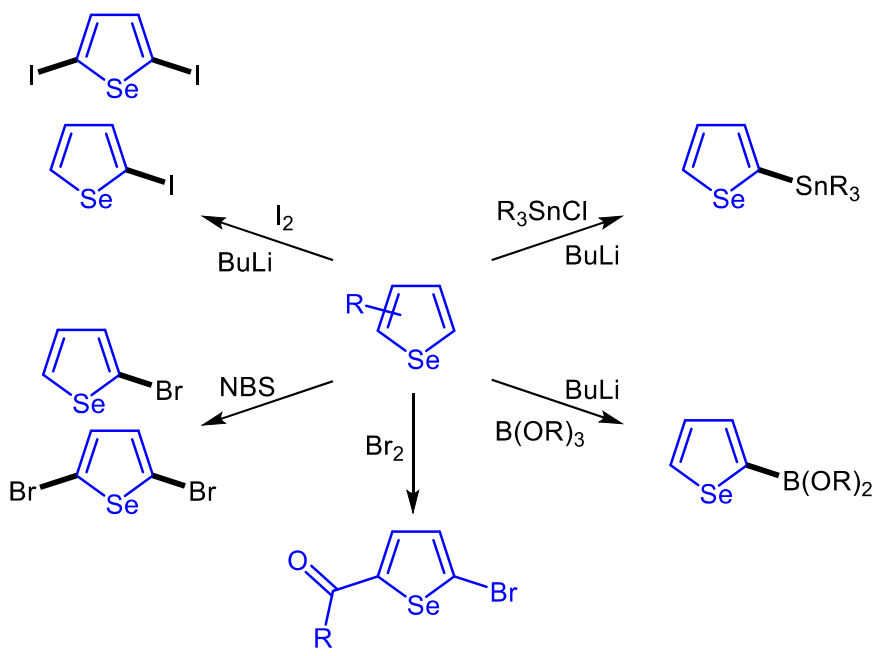

Figure 1

\subsection{C2-arylation via Stille coupling}

The first example of C2-functionalisation of a selenophene via Stille coupling was reported in 1990 by Gronowitz et al. The reaction of 2-(tributylstannyl)selenophene with 5-iodouracil using 5 mol\% $\mathrm{PdCl}_{2}\left(\mathrm{PPh}_{3}\right)_{2}$ catalyst gave the expected coupling product in $45 \%$ yield (Scheme 1). ${ }^{[5]}$ This group also reported in 1990 that from 2,5-dibromothiazole and 2-(tributylstannyl)selenophene, the corresponding 2,5-diheteroarylated thiazole could be obtained in $8 \%$ yield. ${ }^{[4 a]}$ A very similar procedure was employed in 2013 by Srivatsan et al. for the synthesis of an uracil derivative (uridine) containing a selenophene substituent at C5-position. ${ }^{[5 b]}$

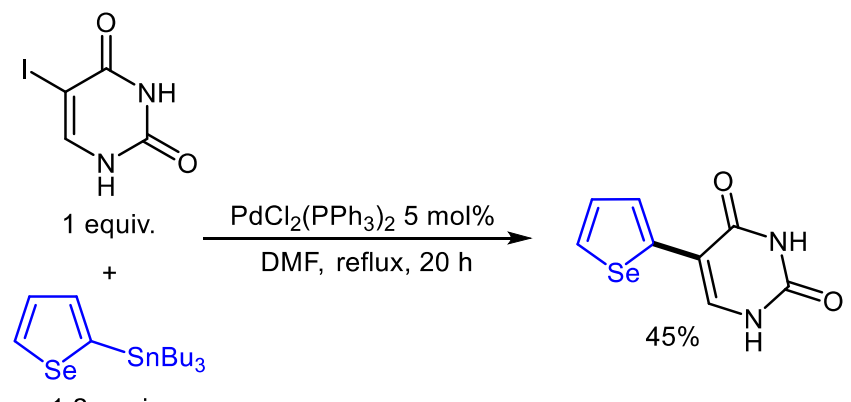

1.2 equiv.

Scheme 1

Since then, Stille coupling has been employed by several groups for access to a variety C2heteroarylated selenophenes (Scheme 2). In 2007, Skabara et al. prepared, via Stille coupling, a conjugated triheteroaryl compound containing a central 1,3,4-thiadiazole and selenophene peripheral 
units in low yield (Scheme 2, top). For this coupling 2,5-dibromo-1,3,4-thiadiazole and (4hexylselenophen-2-yl)trimethylstannane were employed as the coupling partners and 10 mol\% $\mathrm{Pd}\left(\mathrm{PPh}_{3}\right)_{4}$ as catalyst. ${ }^{[6]}$ A better yield of $85 \%$ for the coupling of a 2,5-dibromothiophene derivative with 2-tributylstannylselenophene was obtained by Takiyima et al. (Scheme 2, middle). They performed the reaction with $10 \quad \mathrm{~mol}_{\%} \quad \mathrm{Pd}_{\left(\mathrm{PPh}_{3}\right)_{4}}$ as catalyst in toluene under reflux. ${ }^{[7]}$ 2Tributylstannylselenophene and a 2,5-dibromopyrrole were successfully coupled, under the same reaction conditions, by Hwang, Hyun et al. affording a 2,5-di(selenophen-2-yl)-pyrrole-3,4dicarboxylate in $83 \%$ yield (Scheme 2, middle). ${ }^{[8]}$ These reaction conditions also allowed the preparation of (selenophen-2-yl)thiophenes from a 2-bromoselenophene or 5,5'-dibromo-2,2'biselenophene and a 2-trimethylstannylthiophene (Scheme 2, middle). ${ }^{[1 \mathrm{~b}, 9]}$ An example of Stille coupling of a 2,5-dibromotellurophene with 2-tributylstannylthiophene has also been described with $\mathrm{Pd}\left(\mathrm{PPh}_{3}\right)_{4}$ catalyst, showing that 2-bromo-substituted tellurophene and selenophene exhibit a similar reactivity for this coupling (Scheme 2 , bottom). ${ }^{[10]}$ 


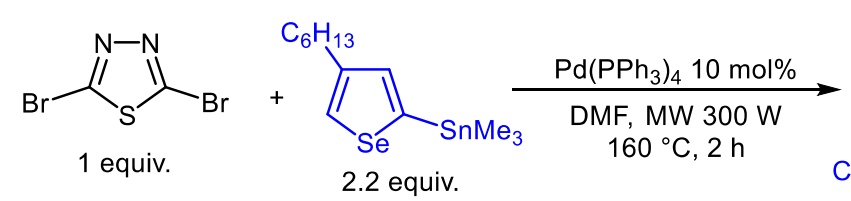

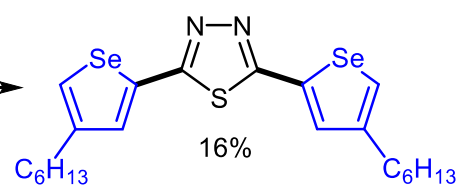

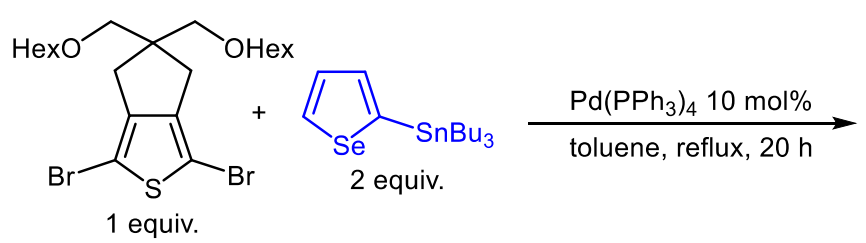<smiles>OCC1(CO)Cc2c(-c3ccc[se]3)sc(-c3ccc[se]3)c2C1</smiles><smiles>CCCCCCCCCCn1c(Br)c(C(=O)OCC)c(C(=O)OCC)c1Br</smiles><smiles>CSc1ccc[se]1</smiles><smiles>CCCCn1c(-c2ccc[se]2)c(C(=O)OCC)c(C(=O)OCC)c1-c1ccc[se]1</smiles>

$83 \%$

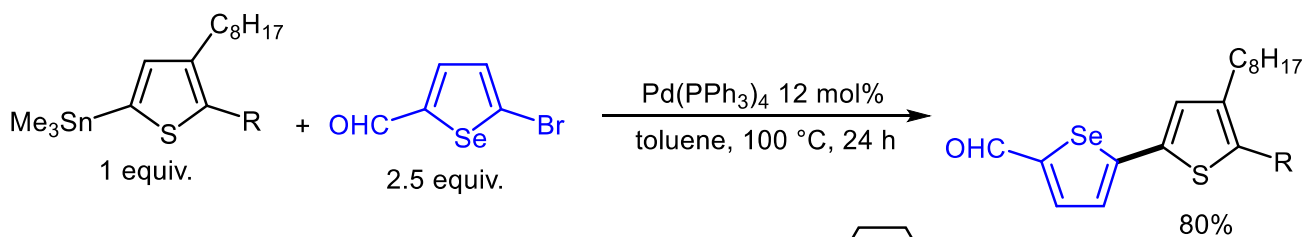<smiles></smiles>
3 equiv.<smiles>CCCCCc1cccs1</smiles><smiles></smiles>

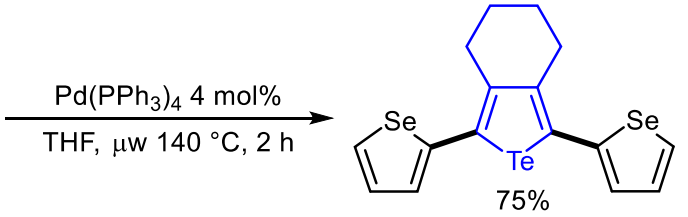

Scheme 2

A few examples of Pd-catalysed C-C bond formation by coupling of two selenophene derivatives have been reported (Scheme 3). For example, Stille reaction allowed to prepare terselenophenes by coupling of a 3-alkyl-2-bromoselenophene with 2,5-bis(trimethylstannyl)selenophene (Scheme 3, top). Moreover, this terselenophene treated by $\mathrm{N}$-bromosuccinimide and then $\mathrm{BuLi} / \mathrm{Me}{ }_{3} \mathrm{SnCl}$ gave the corresponding 5,5'-bis(trimethylstannyl)-terselenophene which, after a second Stille coupling, provides a pentaselenophene derivative. ${ }^{[11 a, b]}$ This procedure also allowed to prepare a tetraselenophene in good yield from a 5,5'-bis(trimethylstannyl)-2,2'-biselenophene and a 2-bromoselenophene (Scheme 3, middle). ${ }^{[1 \mathrm{c}]}$ Another tetraselenophene has been prepared in $80 \%$ yield using a 2 -substituted 5 bromoselenophene and again 5,5'-bis(trimethylstannyl)-2,2'-biselenophene, but with $\mathrm{PdCl}_{2}\left(\mathrm{PPh}_{3}\right)_{2}$ as 
catalyst (Scheme 3, middle). ${ }^{[12]}$ An example of coupling of a thienyl-substituted 2-bromoselenophene with a 2-trimethylstannylthiophene using $\mathrm{Pd}_{2}(\mathrm{dba})_{3}$ associated to $\mathrm{AsPh}_{3}$ as catalytic system has also been reported recently (Scheme 3, bottom). ${ }^{[13]}$

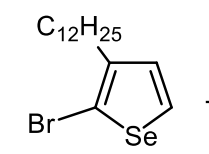

2.6 equiv.

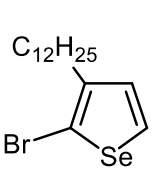

2.1 equiv.

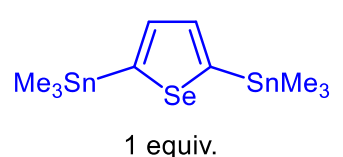

1 equiv.

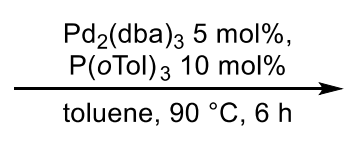

toluene, $90{ }^{\circ} \mathrm{C}, 6 \mathrm{~h}$

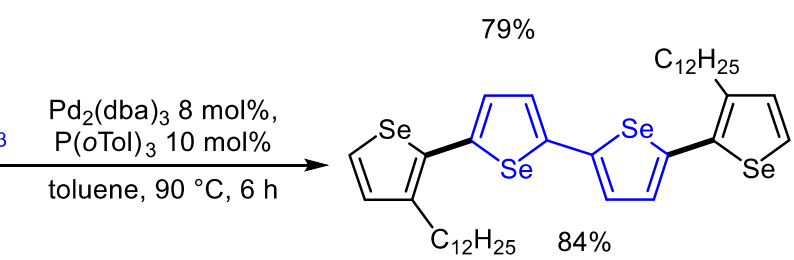

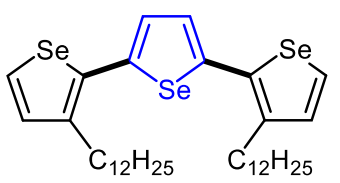

$79 \%$<smiles>N#CC(C#N)=Cc1ccc(Br)[se]1</smiles>

2.5 equiv.

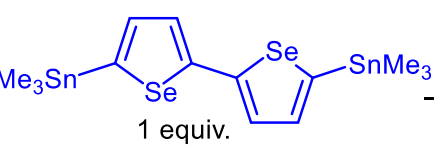

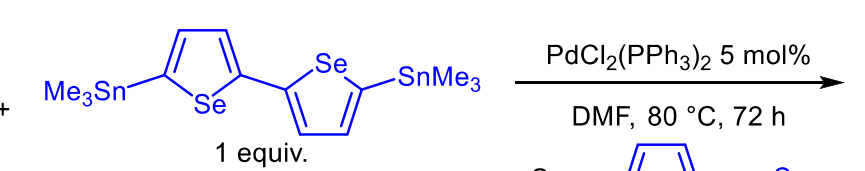<smiles>N#CC(C#N)=Cc1ccc(-c2ccc(-c3ccc(-c4ccc(C=C(C#N)C#N)[se]4)[se]3)[se]2)[se]1</smiles>

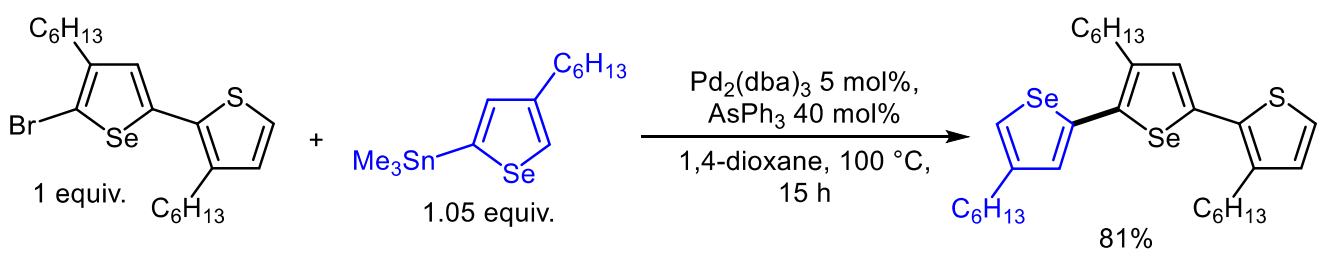

Scheme 3

Benzotriazoles, benzothiadiazoles, benzoxadiazoles or even benzoselenodiazoles are often employed as central units of polyheteroaromatic monomers which are polymerised to prepare organic photovoltaics. In several cases, selenophene substituents have been introduced as peripheral units at C4 and C7 positions on these azole derivatives to tune their physical properties (Scheme 4). ${ }^{[14-17]}$ For example, a 4,7-dibromobenzotriazole, using 2-tributylstannylselenophene as selenophene source, was employed for the synthesis of a 4,7-di(selenophen-2-yl)benzotriazole, which was then polymerized (Scheme 4, top). ${ }^{[14 a]}$ This Stille coupling was performed using $\mathrm{PdCl}_{2}\left(\mathrm{PPh}_{3}\right)_{2}$ as catalyst in THF under reflux. Under the same reaction condition using DMF as solvent, the coupling of 4,7-dibromo$[1,2,5]$ selenadiazolo[3,4-c]pyridine with 2-tributylstannylselenophene gave the corresponding coupling product in $70 \%$ yield. ${ }^{[14 b]}$ From a 4,7-dibromobenzothiadiazole derivative, under similar reaction conditions, the corresponding 4,7-di(selenophen-2-yl)benzothiadiazole was obtained in similar yield (Scheme 4, middle). ${ }^{[15]} \quad$ A 4,7-dibromo-2,1,3-benzoselenodiazole has been reacted with 2(tributylstannyl)-3,4-ethylenedioxyselenophene using $10 \mathrm{~mol} \% \mathrm{Pd}\left(\mathrm{PPh}_{3}\right)_{4}$ as catalyst in toluene $(\mathrm{Scheme}$ 
4, middle). ${ }^{[16]}$ Again the expected 4,7-diheteroarylated benzoselenodiazole derivative was obtained in good yield. The preparation, under the same reaction conditions, of a benzoxadiazole substituted at $\mathrm{C} 4$ and C7 positions by selenophene units from a 4,7-dibromobenzoxadiazole has been reported in 2012 by Zade et al. (Scheme 4, bottom). ${ }^{[17]}$
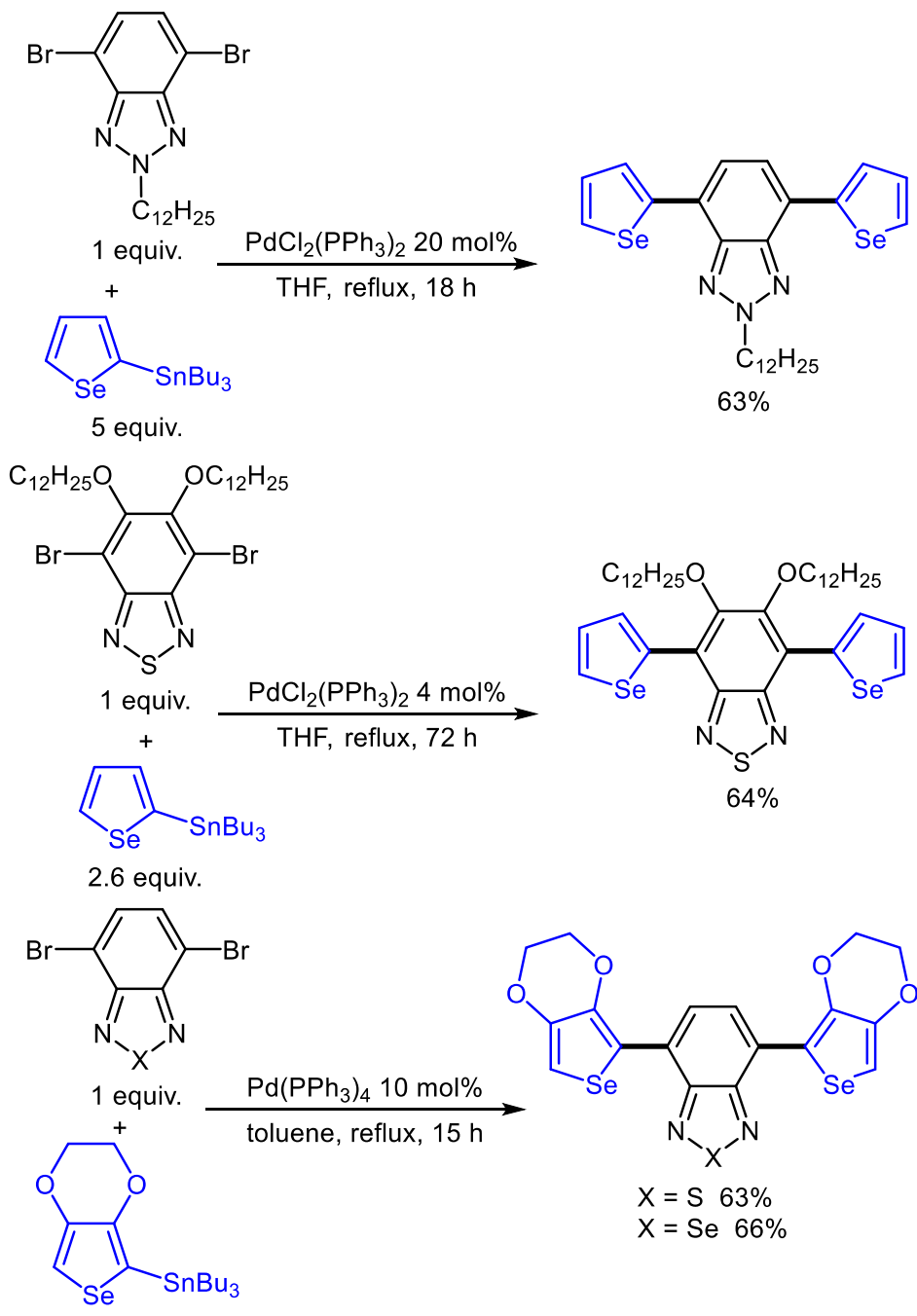

$\mathrm{Pd}\left(\mathrm{PPh}_{3}\right)_{4} 10 \mathrm{~mol} \%$

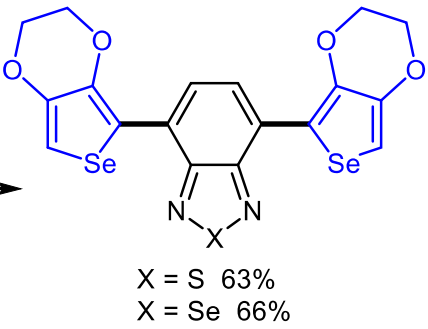

2 equiv.<smiles>Brc1ccc(Br)c2nonc12</smiles>

1 equiv. $\underset{\text { toluene, } 100{ }^{\circ} \mathrm{C}, 24 \mathrm{~h}}{\mathrm{Pd}\left(\mathrm{PPh}_{3}\right)_{4} 10 \mathrm{~mol} \%}$<smiles>CCCCc1ccc[se]1</smiles><smiles>c1c[se]c(-c2ccc(-c3ccc[se]3)c3nonc23)c1</smiles>
$78 \%$

Scheme 4 
In 2009, Toppare et al. prepared an electrochromic polymer from a 1,4-di(selenophen-2-yl)benzene derivative. This monomeric selenophene derivative was obtained by reaction of 1,4-dibromo-2,5bis(hexyloxy)benzene with 2-(tributylstannyl)selenophene via Stille coupling using $\mathrm{PdCl}_{2}\left(\mathrm{PPh}_{3}\right)_{2}$ catalyst and THF as solvent. ${ }^{[18 a, b]}$ The target product was obtained in $35 \%$ yield (Scheme 5, top). Four years later, Jen et al. described that the coupling of 2-(tributylstannyl)selenophene with more electrondeficient diethyl 2,5-dibromoterephthalate, under similar conditions, led to the polyaromatic benzene derivative containing two peripheral selenophene units in a better yield of $89 \%$ (Scheme 5 , middle). ${ }^{[19}$. A quinoxazoline derivative was heteroarylated with 2-(tributylstannyl)selenophene at positions C5 and C8 using the same reaction conditions (Scheme 5, bottom). ${ }^{[20]}$ A good yield of $76 \%$ in the desired product, which was polymerized to prepare polymer semiconductors, was obtained.
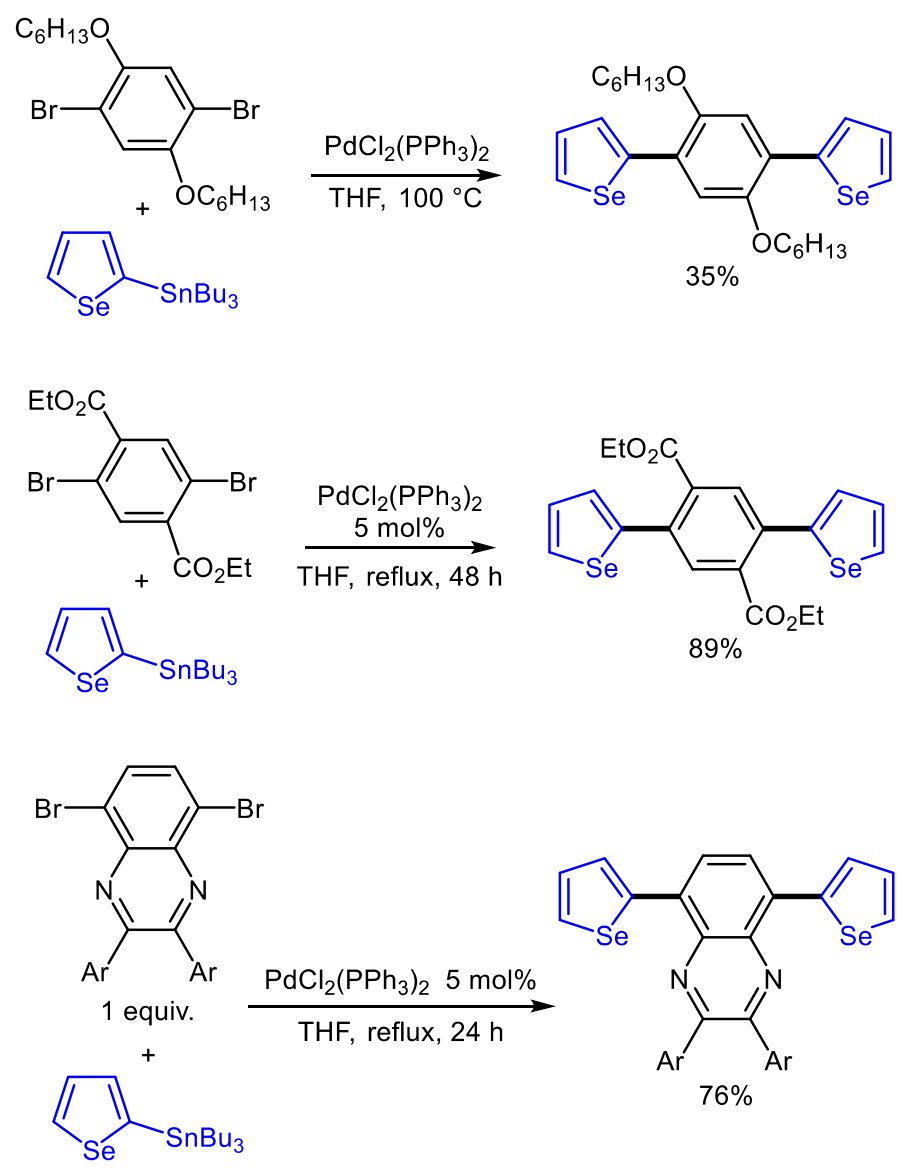

2.4 equiv.

Scheme 5

In 2009, in order to prepare dye-sensitized solar cells based on organic sensitizers, conjugated systems were prepared by Stille coupling using 2-(tributylstannyl)selenophene and a 4-bromoaniline as reaction partners. The expected product was obtained in $50 \%$ yield (Scheme 6 , top). ${ }^{[21]}$ A higher yield of $70 \%$ 
had been obtained by Zade et al. for the synthesis of a very similar compound, using $5 \mathrm{~mol} \% \operatorname{Pd}\left(\mathrm{PPh}_{3}\right)_{4}$ in toluene under reflux as reaction conditions. ${ }^{[22]}$ Wang group also reported in 2009 the coupling of 2hexyl-5-(tributylstannyl)selenophene with 4,4'-dibromo-2,2'-bipyridine. ${ }^{[23]}$ The expected 4,4'-bis(5hexylselenophen-2-yl)-2,2'-bipyridine was obtained in $80 \%$ yield (Scheme 6, middle). A permanently porous hydrogen-bonded organic framework with two $N$-methyliminodiacetic acid (MIDA) boronate termini has been prepared in $87 \%$ yield by Seteros et al. from 2,5-bis(trimethylstannyl)selenophene and an iodobenzene derivative using $\mathrm{Pd}\left(\mathrm{PPh}_{3}\right)_{4}$ as catalyst, $\mathrm{CuI}$ as additive in DMF. (Scheme 6, middle). ${ }^{[24 a}$. Moreover, a 2,5-bis(trimethylstannyl)tellurophene could also be employed for this reaction. It should be mentioned that, under these conditions, the C-B bond remained untouched. The reactivity of selenophene and tellurophene for Stille coupling appears to be similar. For example, the reaction of tributyl(tellurophen-2-yl)stannane with a set of aryl iodides using $2 \mathrm{~mol} \% \mathrm{Pd}\left(\mathrm{PPh}_{3}\right)_{4}$ catalyst also affords the 2-arylated tellurophenes in good yields (Scheme 6, bottom). ${ }^{[24 \mathrm{~b}]}$
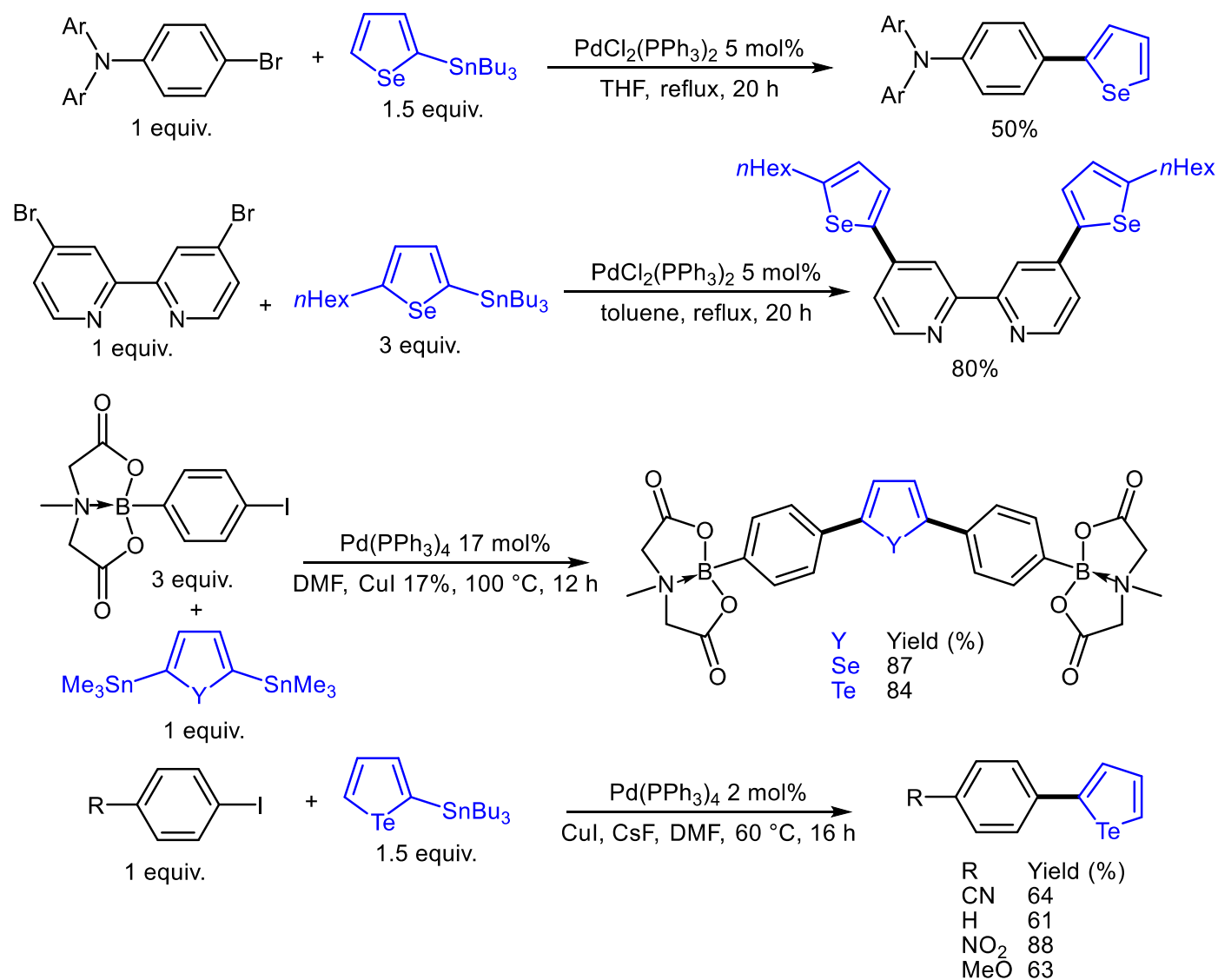

Scheme 6

In summary, both 2-bromoselenophenes and 2-(trialkylstannyl)selenophenes can be employed for such Stille couplings. In most cases, $\mathrm{Pd}\left(\mathrm{PPh}_{3}\right)_{4}$ or $\mathrm{PdCl}_{2}\left(\mathrm{PPh}_{3}\right)_{2}$ were used as the catalysts, but in a few cases, 
$\operatorname{Pd}_{2}(\mathrm{dba})_{3}$ associated to phosphine or arsine ligands were also used. The most common solvents are toluene, THF or DMF and the reactions were generally conducted under reflux. Even if stannyl derivatives are not considered as suitable reaction partners for coupling reactions in terms of "green chemistry", Stille coupling currently represents a very robust methodology for the preparation of a variety of 2-(hetero)arylselenophenes. So far, there was little study on ligand effect in these couplings. It could be a good entry to improve the yields for the most challenging substrates.

\subsection{C2-arylation via Negishi or Kumada couplings}

As selenophen-2-ylzinc halides or selenophen-2-ylmagnesium halides have to be prepared in situ, very few examples of Negishi or Kumada couplings for the synthesis of 2-(hetero)arylselenophenes have been described. In 1988, Zimmer et al. reported the $\mathrm{NiCl}_{2}(\mathrm{dppp})$-catalysed coupling of 2bromoselenophene or 2,5-dibromoselenophene with thiophen-2-ylmagnesium bromide. ${ }^{[25]} \mathrm{A}$ Pdcatalysed Negishi coupling for access to 2-arylated selenophenes was reported in 1996 by Takahashi and Gunji (Scheme 7, top). ${ }^{[26]}$ Using selenophen-2-ylzinc chloride and an aryl bromide in the presence of $\mathrm{Pd}\left(\mathrm{PPh}_{3}\right)_{4}$ catalyst, they obtained the coupling product in $75 \%$ yield. Using similar reaction conditions, tris(4-iodophenyl)amine was found to react with selenophen-2-ylzinc chlorides to afford triheteroarylated triphenylamines in moderate yields (Scheme 7, bottom). ${ }^{[27]}$
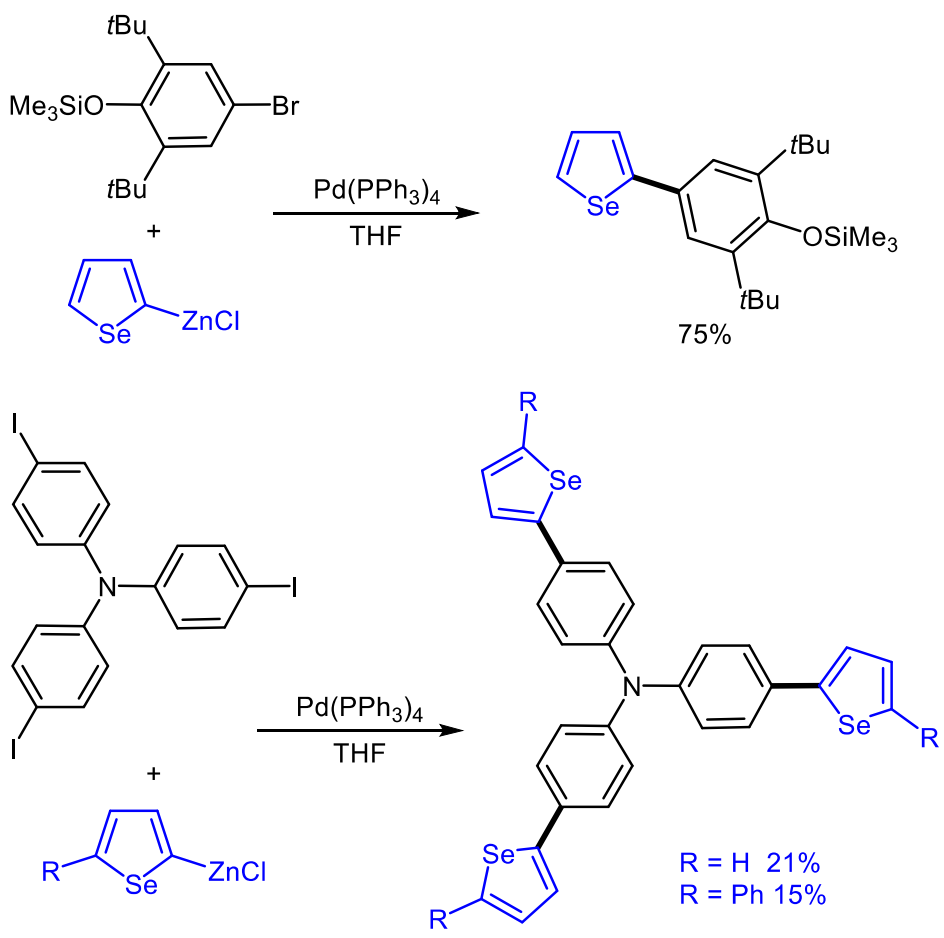

Scheme 7 
In 1996, Nakayama et al. reported that a solution of a (selenopheno[3,2-b]selenophen-2-yl)magnesium bromide could be coupled with a 2-bromoselenopheno[3,2-b]selenophene in the presence of palladium or nickel catalysts (Scheme 8, top). ${ }^{[28 a]}$ The best result was obtained using $5 \mathrm{~mol} \% \mathrm{Pd}\left(\mathrm{PPh}_{3}\right)_{4}$ catalyst, with the formation of coupling product in $85 \%$ yield. They also reported that a solution of a zinc derivative, prepared by treatment of a selenoloselenophene by $n \mathrm{BuLi}$ followed by addition of $\mathrm{ZnBr}_{2}$, reacts with a 2-bromoselenopheno[3,2-b]selenophene to give the corresponding trimer in $31 \%$ yield (Scheme 8, middle). Based on these results, Chi, Shim et al. reported in 2009 the coupling of 2bromothiophene with a 2-bromoselenophene derivative in the presence of magnesium and a palladium catalyst (Scheme 8 , bottom). ${ }^{[28 b]}$ The target product was obtained in $79 \%$ yield. This reaction proceeds via the formation of a thiophen-2-ylmagnesium bromide intermediate. The polymerization of a 2bromo-3-octylselenophen5-yl zinc bromide for the synthesis of a poly(3-octylselenophene) via palladium-catalysis has also been described. ${ }^{[28 c]}$
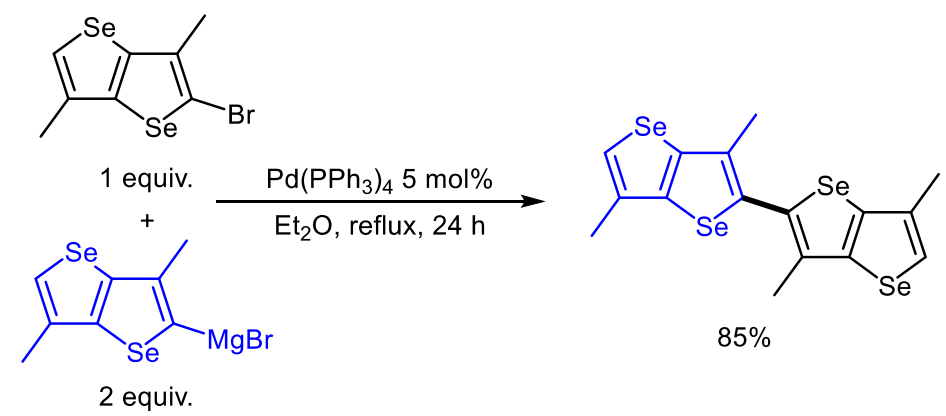

$85 \%$

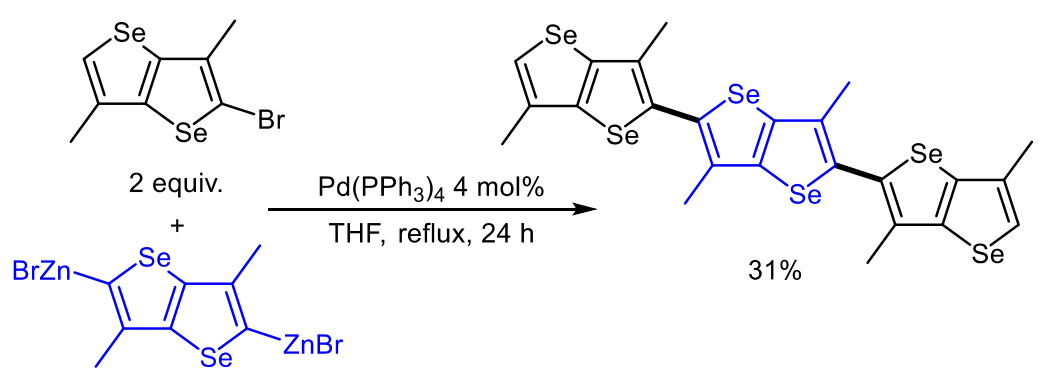

1 equiv.
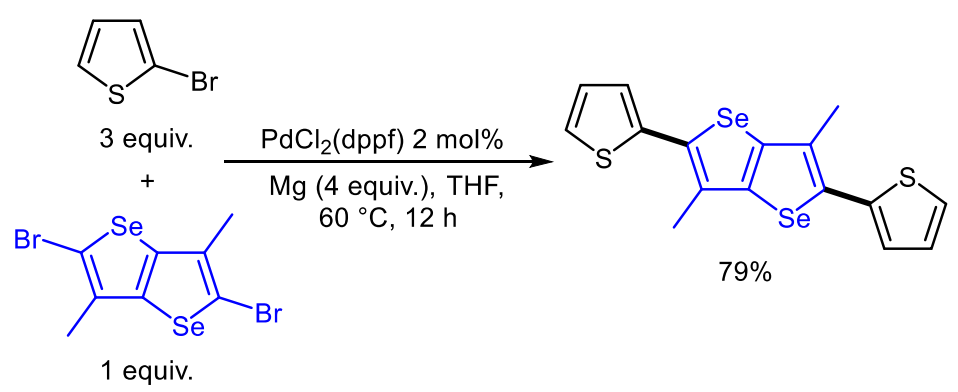

Scheme 8 
In summary, if a few examples of Pd-catalysed Negishi or Kumada couplings using selenophen-2-ylzinc chlorides have been reported, it does not appear to be the most convenient route to prepare 2(hetero)arylated selenophenes, as freshly prepared prepared solutions of the zinc or magnesium derivatives were generally employed.

\subsection{C2-arylation via Suzuki coupling}

Over the last decade, several examples of synthesis of 2-arylselenophenes employing Suzuki coupling have been described (Schemes 9-17). In 2005, Takimiya et al. reported the reaction of 2,5dibromoselenophene or 5,5'-dibromo-2,2'-biselenophene with pentafluorophenylboronic acid (Scheme 9). ${ }^{[29 a}$ The diarylated selenophene derivatives were obtained in good yield using $\mathrm{Pd}\left(\mathrm{PPh}_{3}\right)_{4}$ as catalyst in the presence of a mixture of $\mathrm{Ag}_{2} \mathrm{O}$ and $\mathrm{K}_{3} \mathrm{PO}_{4}$ as bases. They employed a similar procedure for the 2,6-diarylation of a 2,6-diiodobenzodiselenophene using 4-fluoro-, 4-cyano- or 4-trifluoromethylbenzeneboronic acids and also pentafluorophenylboronic acid as aryl sources. ${ }^{[29 b]}$

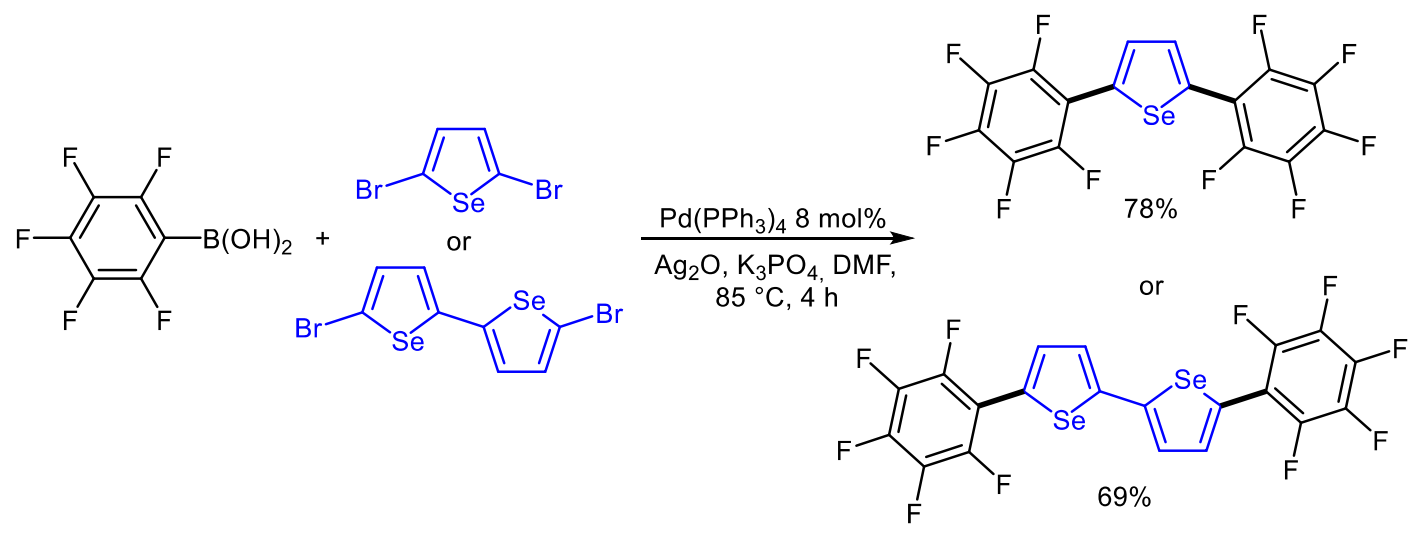

Scheme 9

One year later, Zeni et al. studied the scope of the synthesis of 2-arylselenophenes via Suzuki coupling using 2-iodoselenophene, 2-bromoselenophene and also 2,5-diiodoselenophene. ${ }^{[30]}$ The reaction of 2 iodoselenophene with arylboronic acids bearing electron-withdrawing or electron-donating substituents proceeded cleanly in the presence of $3 \mathrm{~mol} \% \mathrm{Pd}(\mathrm{OAc})_{2}, \mathrm{~K}_{2} \mathrm{CO}_{3} / \mathrm{H}_{2} \mathrm{O}$ in DME (Scheme 10, top). As these reaction conditions gave lower yields with 2-bromoselenophene than with the corresponding iodide, they modified the catalytic system to $3 \mathrm{~mol} \% \mathrm{Pd}\left(\mathrm{PPh}_{3}\right)_{4}$, using toluene as solvent and $\mathrm{Na}_{2} \mathrm{CO}_{3}$ as base. Under these conditions, 2-bromoselenophene was coupled with arylboronic acids bearing 
electron-withdrawing or electron-donating substituents in similar yields (Scheme 10, middle). They also investigated, the possibility of generating 2,5-diarylselenophenes from 2,5-diiodoselenophene and arylboronic acids. Under the same reaction conditions described for the coupling with 2iodoselenophene, the 2,5-diarylated selenophene derivatives were formed in good yields (Scheme 10, bottom). This method was employed by Kimura and Murakami for the preparation of 2,5diphenylselenophene. ${ }^{[31]}$

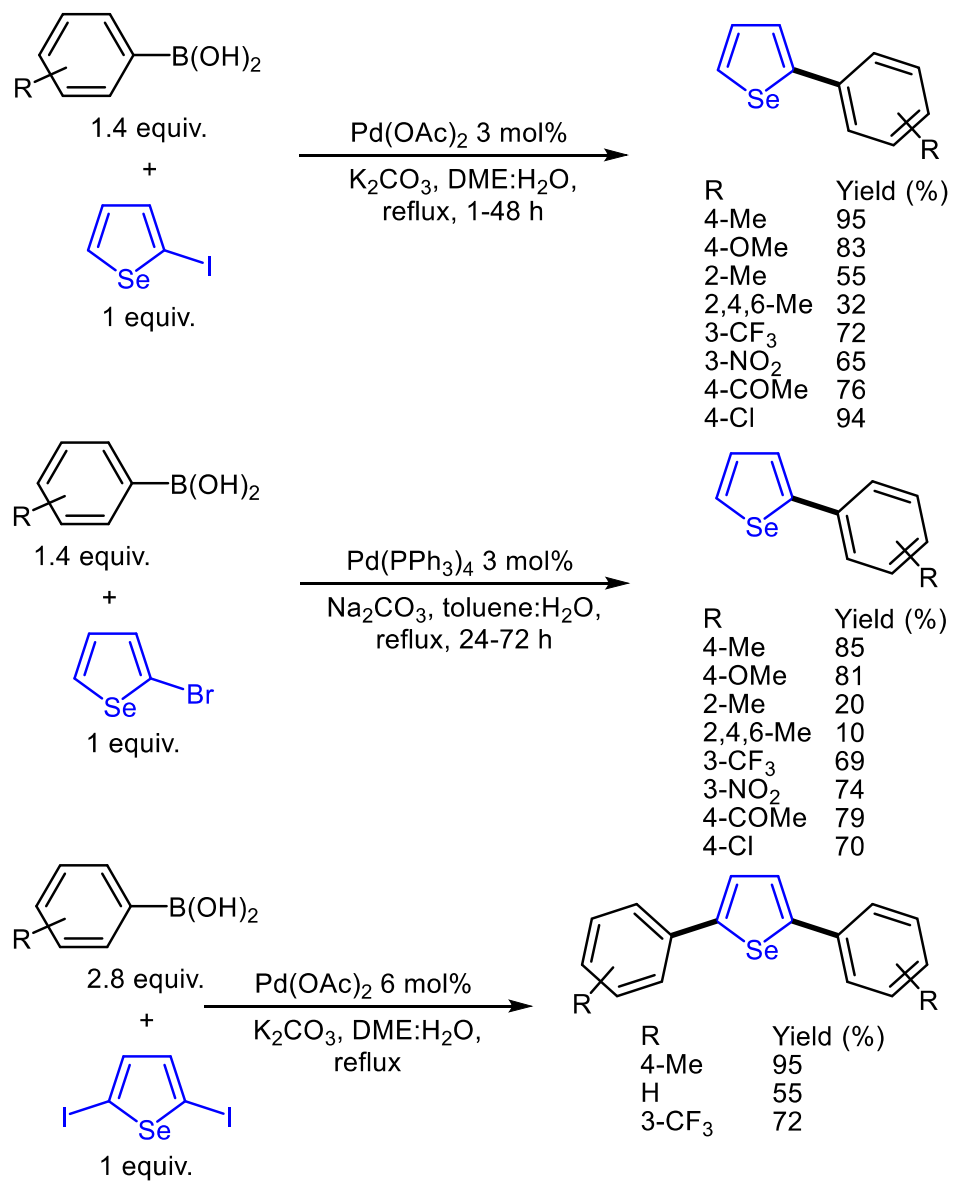

Scheme 10

Hartman et al. employed a quite similar procedure to prepare 2,5-diphenol-substituted selenophenes (Scheme 11). ${ }^{[32 \mathrm{a}]}$ Target compounds were obtained in moderate yields, under microwave assisted conditions in a mixture of DME/EtOH/water as solvent using $\mathrm{Cs}_{2} \mathrm{CO}_{3}$ as base and only $0.1 \mathrm{~mol} \%$ $\mathrm{Pd}\left(\mathrm{PPh}_{3}\right)_{4}$ as catalyst (Scheme 11, top). 2,5-Dibromoselenophene also reacted nicely with 4pyridineboronic pinacol ester using $4 \quad \mathrm{~mol} \% \quad \mathrm{Pd}\left(\mathrm{PPh}_{3}\right)_{4}$ as catalyst, affording 4,4'-(2,5selenophenediyl)bispyridine in $83 \%$ yield (Scheme 11 , middle) ${ }^{[1 \mathrm{c}]}$ A slightly different procedure was employed by Fujita et al. for the preparation of a selenophene ligand containing pyridine units at C2- 
and C5-positions (Scheme 11, bottom). This ligand was used for the self-assembly synthesis of a spherical structure that contains 30 palladium ions and 60 selenophene ligands. ${ }^{[32 \mathrm{~b}]}$

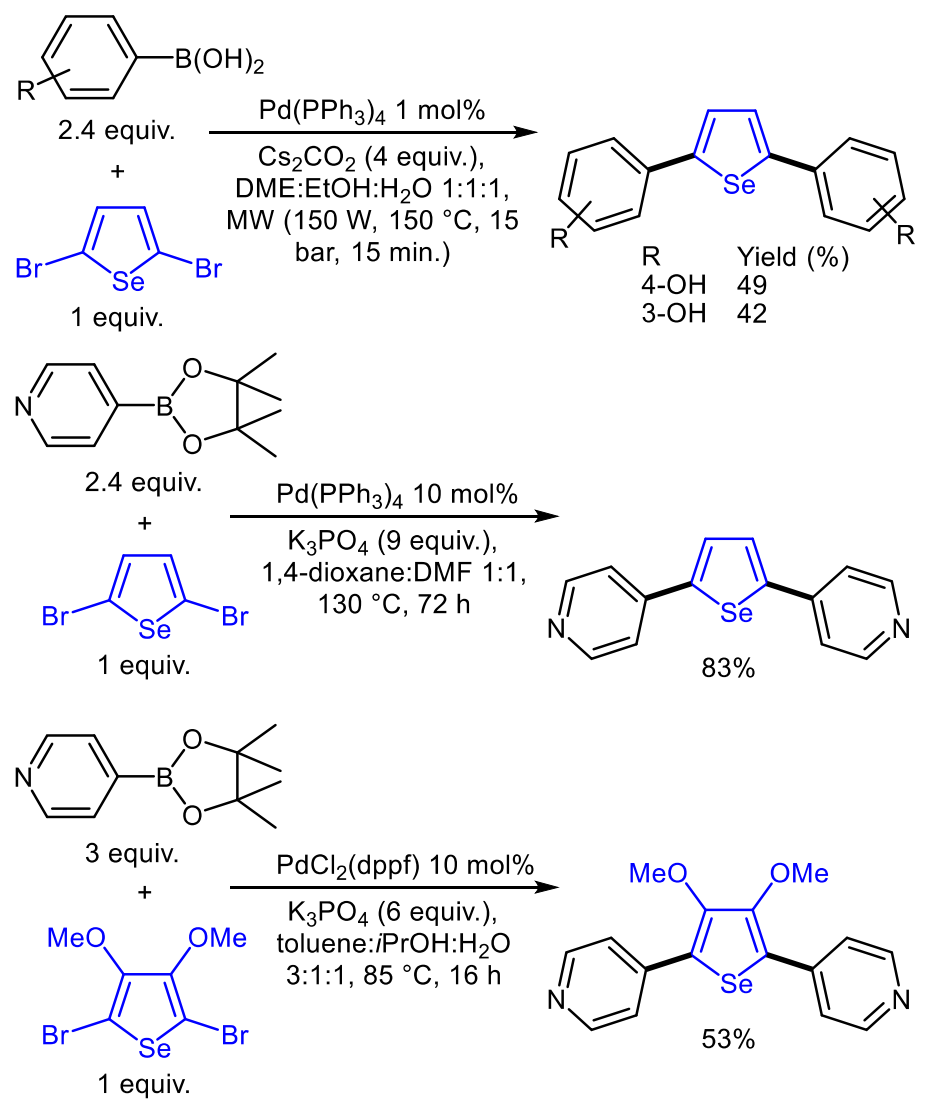

Scheme 11

In 2008, Langer et al. studied the reactivity of 2,3,4,5-tetrabromoselenophene, which can be obtained in high yield by reaction of selenophene with an excess of bromine (7 equiv.) in $\mathrm{CH}_{2} \mathrm{Cl}_{2}$ at $0{ }^{\circ} \mathrm{C}$, in Suzuki coupling (Scheme 12). ${ }^{[33]}$ In the presence of 1.3 equiv. of arylboronic acids, they obtained the monoC2-arylated 3,4,5-tribromoselenophene derivatives in 47-68\% yields. Then, one of these monoarylated compounds, reacted with an other arylboronic acid, gave the non-symmetrical 2,5-diarylated 3,4dibromoselenophene in $80 \%$ yield (Scheme 12, top). Symmetrical 2,5-diarylated 3,4dibromoselenophenes can be obtained in moderate to high yields in one step from 2,3,4,5tetrabromoselenophene using 2.1 equiv. of arylboronic acids and $5 \mathrm{~mol} \% \mathrm{Pd}(\mathrm{OAc})_{2} / \mathrm{SPhos}$ or $5 \mathrm{~mol} \%$ $\mathrm{Pd}\left(\mathrm{PPh}_{3}\right)_{4}$ as catalysts (Scheme 12, bottom). Slightly lower yields were generally obtained in the presence of $\mathrm{Pd}\left(\mathrm{PPh}_{3}\right)_{4}$. It should be mentioned that there are some drawbacks to this methodology as 2,3,4,5-tetrabromoselenophene is a quite unstable compound which has to be stored at $-18{ }^{\circ} \mathrm{C}$ under argon; moreover, the separation of the mono- and di-arylated products is difficult. 

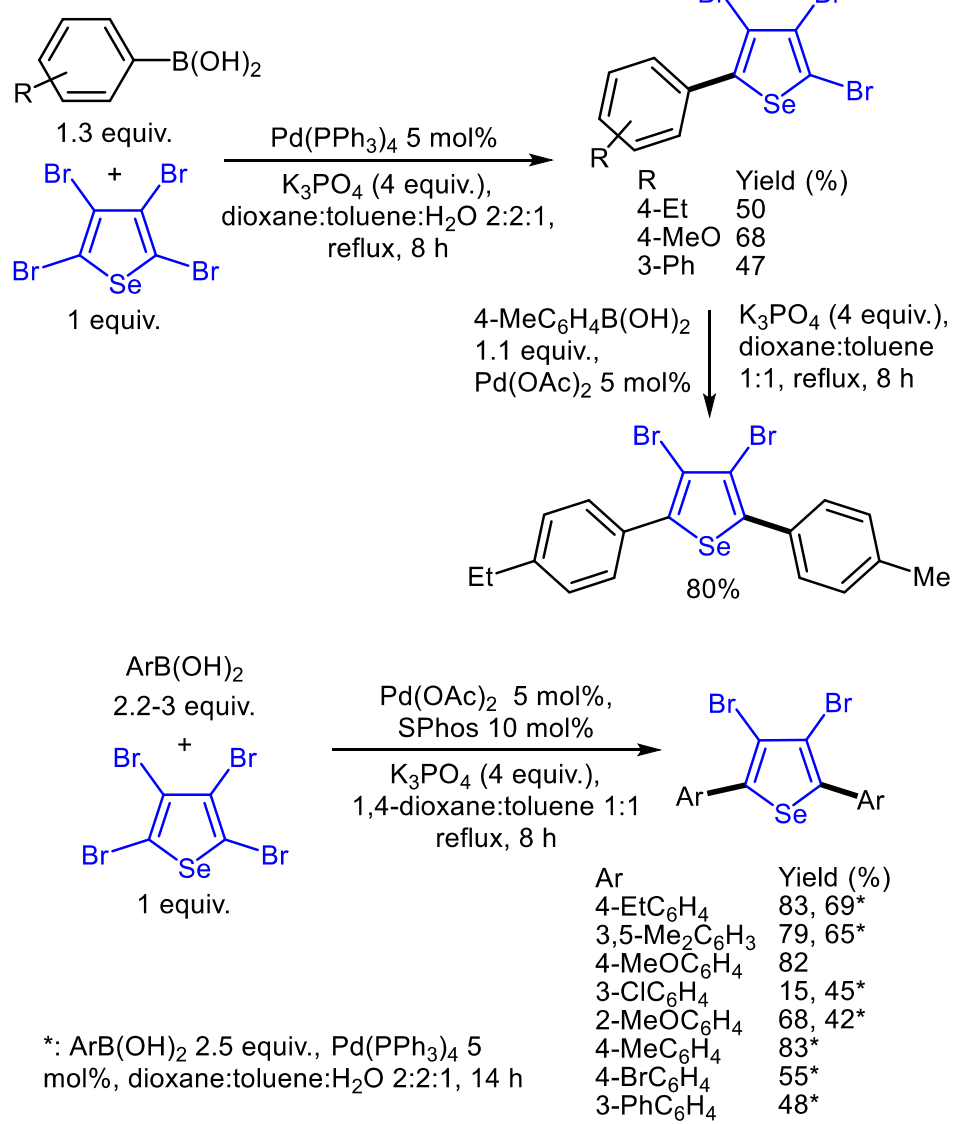

Scheme 12

Selenophenes bearing two peripheral thiophene or furan units at $\mathrm{C} 2$ and $\mathrm{C} 5$ positions have been prepared via Suzuki coupling using 2,5-dibromoselenophene (Scheme 13). Its reaction with 2thienylboronate, using $5 \mathrm{~mol} \%$ of a Pd-carbene catalyst, affords the 2,5-dithienylselenophene in $49 \%$ yield (Scheme 13, top). ${ }^{[34,35]}$ Similar synthetic routes were employed to prepare 5,5'-(selenophene-2,5diyl)bis(furan-2-carbaldehyde) (Scheme 13, middle) ${ }^{[36]}$ and 2,5-bis(3-hexylthiophenyl)selenophene (Scheme 13, bottom). ${ }^{[37]}$ It should be mentioned that the formyl function of the furan derivative was not protected. 

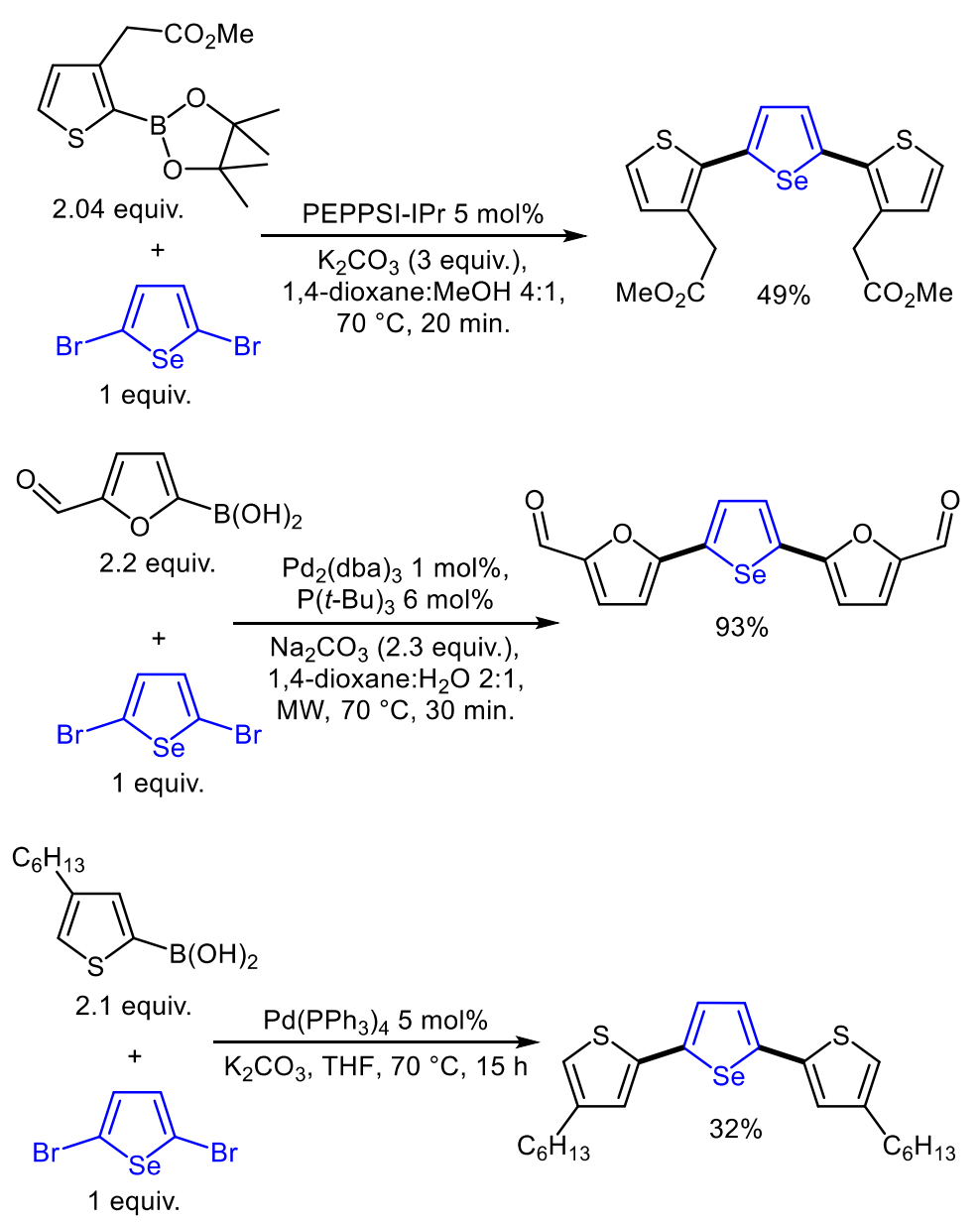

\section{Scheme 13}

Suzuki coupling has been employed by Park, Shim et al. for the synthesis of 5,5'-bis(3-dodecylthiophen2-yl)-2,2'-biselenophene using 5,5'-dibromo-2,2'-biselenophene and a thiophen-2-yldioxaborolane as reaction partners (Scheme 14, top). ${ }^{[38 a]}$ They obtained the expected tetraheteroaromatic product in $53 \%$ yield using $5 \mathrm{~mol} \% \mathrm{Pd}\left(\mathrm{PPh}_{3}\right)_{4}$ catalyst in a mixture of toluene and water as solvent and $\mathrm{Na}_{2} \mathrm{CO}_{3}$ as base. Using the same reaction conditions, they also diheteroarylated 2,5-dibromo-3,6dimethylselenopheno[3,2-b]selenophene (Scheme 14, middle). ${ }^{[38 b]}$ McCullough et al. employed slightly different reaction conditions for the coupling of 2,5-dibromoselenopheno[3,2-b]thiophene with a thiophen-2-yldioxaborolane (Scheme 14, bottom). ${ }^{[39]}$ These selenium-sulphur ring systems were employed as building blocks for the preparation of polymers used in field effect transistors. 

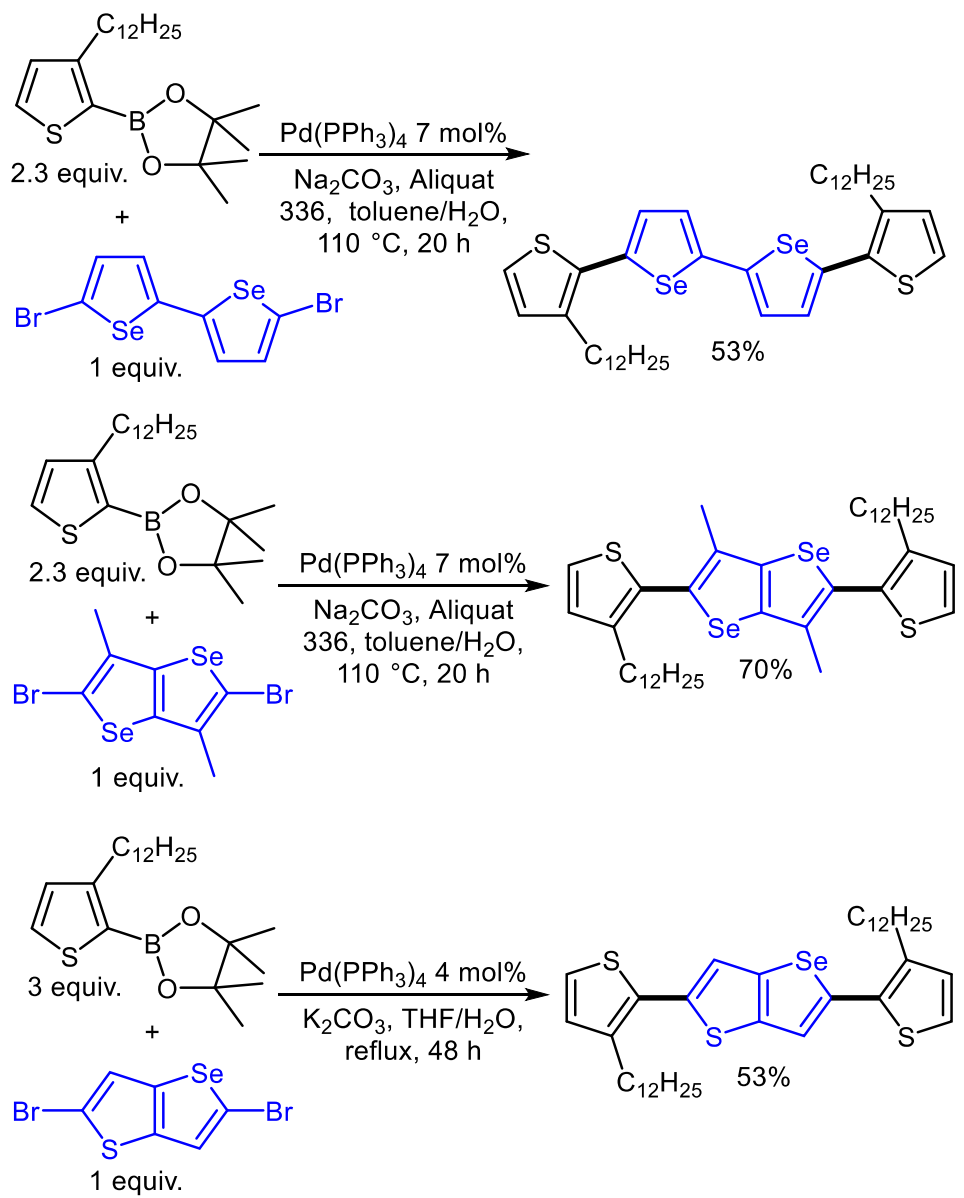

Scheme 14

Suzuki reaction with selenophenes is not limited to the coupling of 2-haloselenophenes with arylboronic acids. Reversing the pattern of halide and boronate also provides the 2 -arylselenophene derivatives. For example, 5-bromopyrimidines and selenophen-2-ylboronic acid in the presence of $\mathrm{Pd}\left(\mathrm{PPh}_{3}\right)_{4}$ catalyst led to the 2-heteroarylated selenophenes in $48-58 \%$ yields (Scheme 15, top). ${ }^{[40]}$ The reaction of selenophen2-ylboronic acid and a 4-chloropyrrolo[2,3-d]pyrimidine derivative in the presence of $5 \mathrm{~mol} \% \mathrm{Pd}(\mathrm{OAc})_{2}$ and $12 \mathrm{~mol} \%$ TPPTS as catalytic system (TPPTS: 3,3',3"-phosphanetriyltris(benzenesulfonic acid) trisodium salt) also gave the corresponding 2-heteroarylselenophene in 64\% yield (Scheme 15 , bottom). ${ }^{[41]}$ 

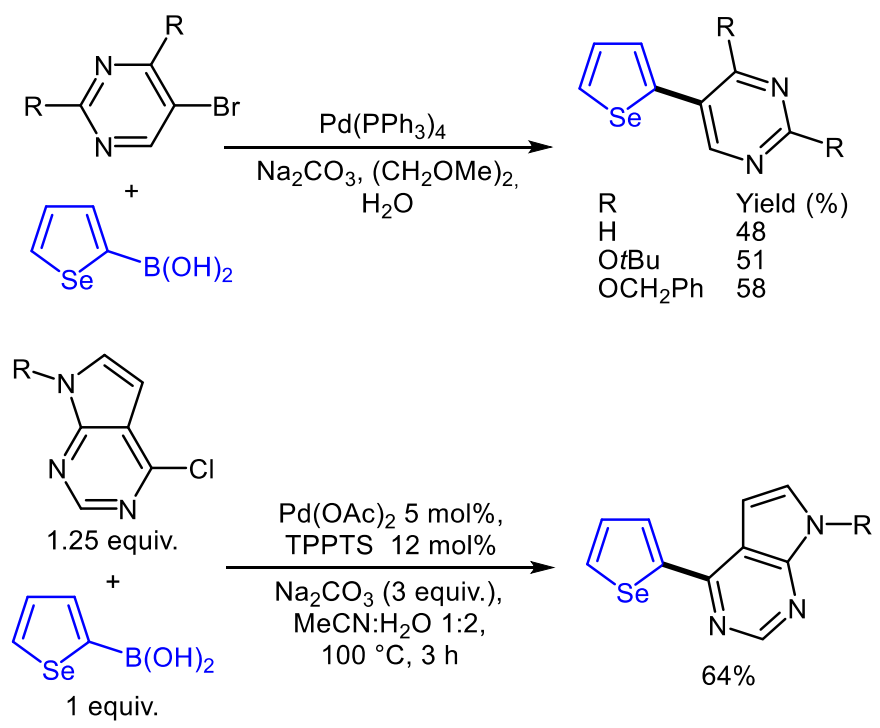

Scheme 15

In 1990, a terselenophene has been prepared in low yield by Zimmer et al. from 2,5dibromoselenophene and selenophen-2-ylboronic acid (Scheme 16, top); ${ }^{[42]}$ whereas, 4,4,5,5tetramethyl-2-(selenophen-2-yl)-1,3,2-dioxaborolane reacts nicely with a 2-iodothiophene derivative at room temperature, affording the expected pentamer in $96 \%$ yield (Scheme 16, middle). ${ }^{[4 \mathrm{~d}, 43]}$ The use of 4.3 equiv. of selenophen-2-ylboronic acid in the presence of 2,7-dibromobenzo[1,2-b:4,3-b']dithiophene and $2.5 \mathrm{~mol} \%$ of $\mathrm{Pd}(\mathrm{dppf}) \mathrm{Cl}_{2}$ with $\mathrm{KF}$ as base gave the corresponding 2,7-diarylated benzo[1,2-b:4,3$\mathrm{b}^{\prime}$ ]dithiophene in $60 \%$ yield (Scheme 16 , bottom). ${ }^{[44]}$ This polyaromatic compound was employed as monomer for the preparation of polymers with optoelectronic properties. 

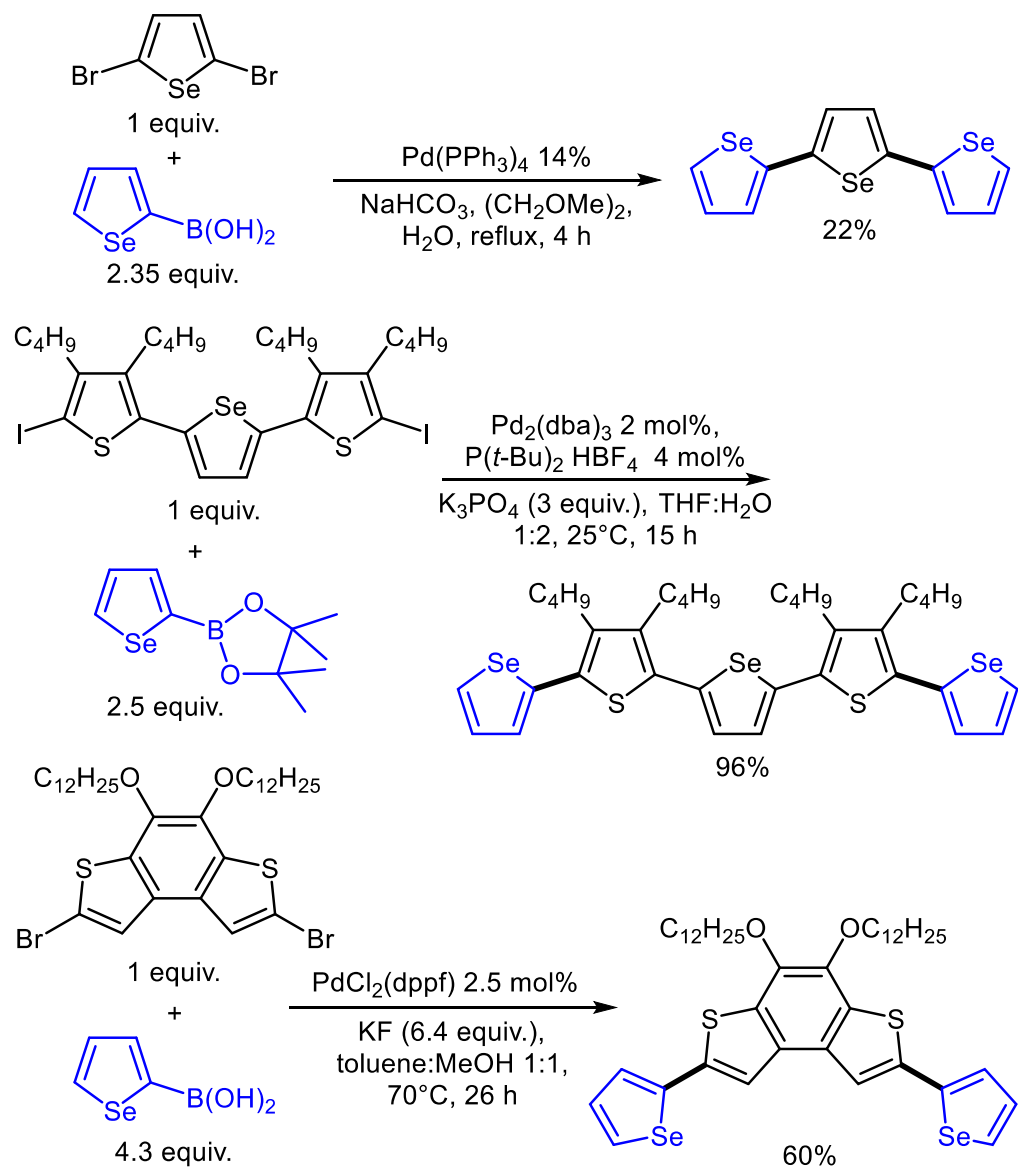
$\mathrm{Pd}_{2}(\mathrm{dba})_{3} 2 \mathrm{~mol} \%$,
$\mathrm{P}(\mathrm{t}-\mathrm{Bu})_{2} \mathrm{HBF}_{4} 4 \mathrm{~mol} \%$
$\underset{\mathrm{K}_{3} \mathrm{PO}_{4}(3 \text { equiv. }), \mathrm{THF}: \mathrm{H}_{2} \mathrm{O}}{\longrightarrow}$

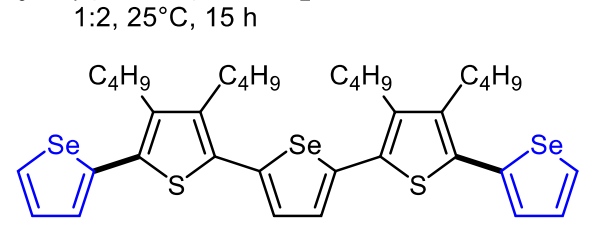

$96 \%$

Scheme 16

The reactivity of 4,4,5,5-tetramethyl-2-(selenophen-2-yl)-1,3,2-dioxaborolane with a 2-bromothiophene or a 2,5-dibromothiophene has been reported by Nilsson et al. (Scheme 17). ${ }^{[34]}$ From an equimolar mixture of the 2-bromothiophene and this selenophene derivative in the presence of $5 \mathrm{~mol} \%$ of $[1,3$ bis(2,6-diisopropylphenyl)imidazol-2-ylidene](3-chloropyridyl)palladium(II) dichloride catalyst, methyl 2-(2-(selenophen-2-yl)thiophen-3-yl)acetate was formed in 73\% yield (Scheme 17, top). Moreover, from a 2,5-dibromothiophene and 2 equiv. of the selenophene derivative, a good yield in the desired 2,5di(selenophen-2-yl)thiophene derivative was also obtained (Scheme 17, middle). The diheteroarylation of a dibromoterthiophene under the same reaction conditions also proceeded in good yield (Scheme 17. bottom). 


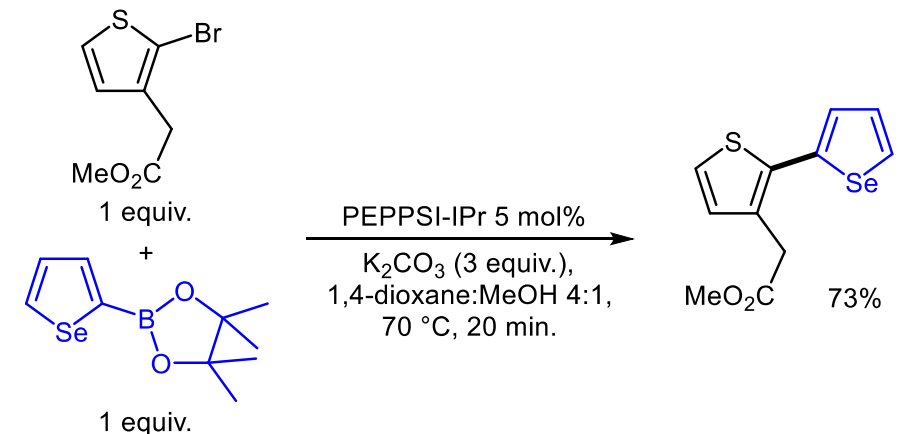<smiles>COC(=O)Cc1cc(Br)sc1Br</smiles><smiles>CC12CC1(C)OB(c1ccc[se]1)O2</smiles>

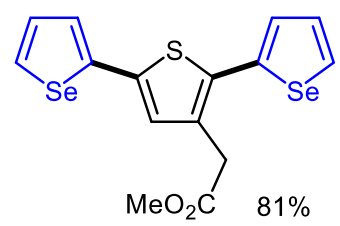

2 equiv.

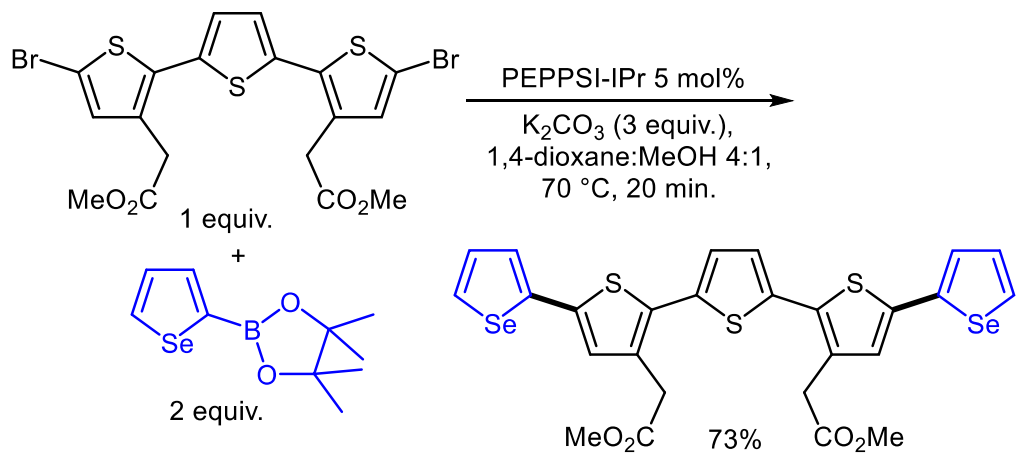

PEPPSI-IPr: [1,3-Bis(2,6-Diisopropylphenyl)imidazol-2-ylidene](3chloropyridyl)palladium(II) dichloride

\section{Scheme 17}

In summary, since the first report in 1990 by Gronowitz and Zimmer on the coupling of bromopyrimidines with selenophen-2-ylboronic acid, the scope of Suzuki coupling for the preparation of 2-(hetero)arylated selenophenes has been largely extended. Both 2-haloselenophenes (with halo $=\mathrm{Br}$ or I) and selenophen-2-ylboronic acids (or the corresponding boronate esters) can be employed. In most cases, $\mathrm{Pd}\left(\mathrm{PPh}_{3}\right)_{4}$ catalyst was employed, but $\mathrm{Pd}(\mathrm{OAc})_{2}$ in some cases associated to phosphine ligands is also a very effective catalyst precursor. One of the major interest of such couplings is that they can be performed under quite low temperatures or even at room temperature. 


\subsection{C2-arylation via $\mathrm{C}-\mathrm{H}$ bond functionalization}

Since the first report in 1982 by Nakamura, Tajima and Sakai on the arylation of isoxazoles via $\mathrm{C}-\mathrm{H}$ bond activation, ${ }^{[45]}$ the palladium-catalysed direct arylation of 5-membered ring heteroaromatics with aryl (pseudo)halides, has emerged as one of the most powerful methods allowing a simple and easy access to arylated heteroaryl derivatives. ${ }^{[i \mathrm{i}, j]}$ A chief advantage of this protocol is that the major byproducts are HX associated to a base instead of metallic or boron salts with the more classical Stille, Negishi or Suzuki couplings. Moreover, no prior preparation of an organometallic or boron derivative is required, reducing the number of steps required to prepare these compounds. For these reasons, $\mathrm{C}-\mathrm{H}$ bond functionalisation provides an economically viable and environmentally attractive access to arylated heterocycles. For the intermolecular direct arylation of benzene derivatives, in most cases, the regioselectivity of the couplings is controlled by directing groups. However, this method is rarely employed in the presence of 5-membered ring heteroaromatics, as the inherent electronic bias of such heterocycle generally allows to control the regioselectivity of the arylation reaction.

In 2011, Mori, Kumura et al. reported the first example of a Pd-catalysed arylation of a selenophene derivative via a $\mathrm{C}-\mathrm{H}$ bond activation. ${ }^{[46]}$ From 2-formylselenophene and a set of aryl iodides in the presence of $5 \mathrm{~mol} \% \mathrm{PdCl}_{2}\left(\mathrm{PPh}_{3}\right)_{2}$, the $\mathrm{C} 5$-arylated selenophenes were regioselectively obtained in 46$69 \%$ yields (Scheme 18, top). Both electron-rich and electron-poor aryl bromides were successfully employed. The reaction of a 2-formylbiselenophene with 9-ethyl-3-iodocarbazole under the same reaction conditions also gave the expected arylated biselenophene derivative in $52 \%$ yield, which was used to prepare a seleno analogue of an organic dye molecule employed as dye-sensitized solar cell (Scheme 18, middle). The regioselectivity observed for these direct arylations is similar to those generally observed in the Pd-catalyzed direct arylations of furans, thiophenes or pyrroles, which proceed via a concerted metallation deprotonation mechanism. ${ }^{[3 \mathrm{q}, \mathrm{r}]}$ It should be mentioned that the homocoupling of 2-formylselenophene can be performed in the presence $\mathrm{PdCl}_{2}\left(\mathrm{PhCN}_{2}\right.$ catalyst with $\mathrm{AgNO}_{3} / \mathrm{KF}$ as base/oxidant in DMSO (Scheme 18, bottom). 

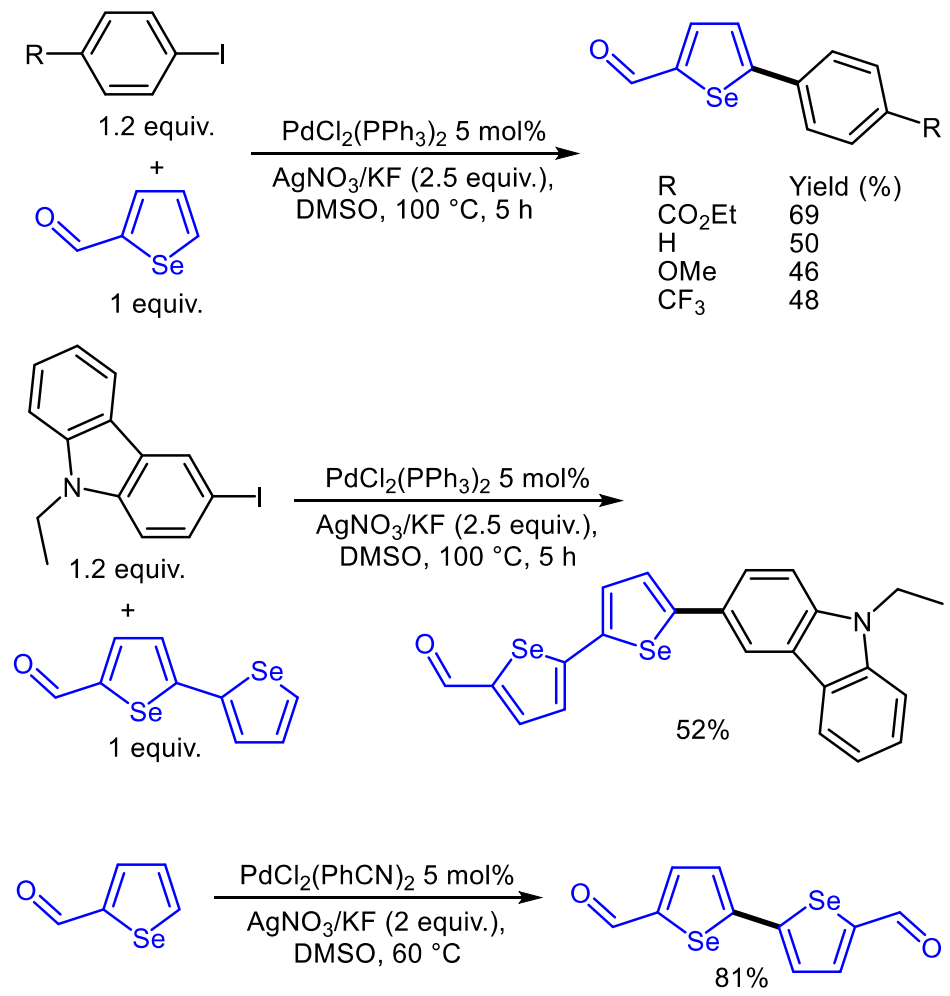

Scheme 18

In 2014, Schneider et al. investigated the influence of several reaction conditions on the reactivity of selenophenes in Pd-catalysed direct arylation using aryl bromides and aryl iodides as coupling partners (Scheme 19). ${ }^{[47]}$ The best results were obtained with $4 \mathrm{~mol} \% \mathrm{Pd}(\mathrm{OAc})_{2}$ associated to $16 \mathrm{~mol}^{\circ} \mathrm{PPh}_{3}$ as ligand, $\mathrm{K}_{2} \mathrm{CO}_{3}$ as the base and $\mathrm{PivOH}$ as additive in DMF at $100{ }^{\circ} \mathrm{C}$ (Scheme 19 , top). Lower yields were obtained with $\mathrm{Cs}_{2} \mathrm{CO}_{3}, \mathrm{~K}_{3} \mathrm{PO}_{4}$ or KOAc bases and with electron-rich phosphine ligands such as $\mathrm{PCy}_{3}$. In all cases, the reaction was highly regioselective in favour or the arylation at C2-position of selenophene. In general, slightly higher yields were obtained with aryl iodides than aryl bromides as aryl source. The reaction tolerated a wide variety of functional groups on the aryl halide, such as nitro, chloro, ester, acetyl or methoxy. 3-Bromopyridine or congested 2-bromotoluene were also successfully employed. Using an excess of aryl iodide, the formation of 2,5-diarylated selenophenes in 54-62\% yields was possible (Scheme 19, middle). Finally, from 2-arylated selenophenes, a second arylation at C5-position using another aryl iodide allowed the formation of non-symmetrical 2,5-diarylselenophenes in high yields (Scheme 19, bottom). 


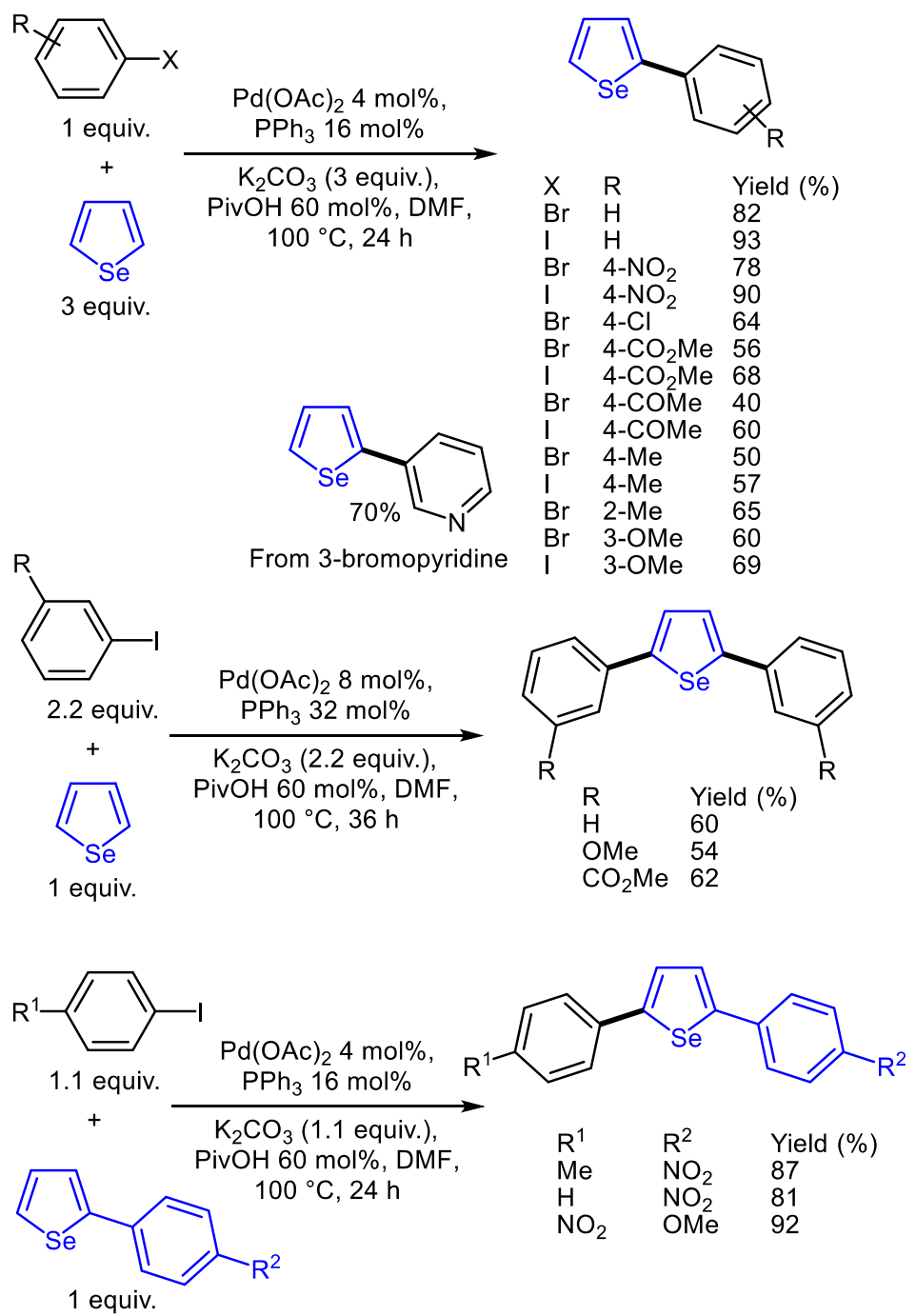

Scheme 19

Although no detailed mechanistic studies have been performed for such Pd-catalysed direct arylations of selenophenes, concerted metallation-deprotonation (CMD) pathway can be proposed. Fagnou and coworkers reported that the experimental and computational data support the involvement of a CMD pathway for $\pi$-excessive aromatics such as furans, thiophenes, pyrroles or thiazoles with aryl(pseudo)halides. ${ }^{[48]}$ The first step of the catalytic cycle is certainly the oxidative addition of the aryl halide to palladium (Scheme 20). Then, after coordination of selenophene to palladium, a concerted metallation-deprotonation, followed by reductive elimination affords the 2-arylated selenophene. However, electrophilic aromatic substitution or Heck type reaction mechanisms cannot be excluded. 


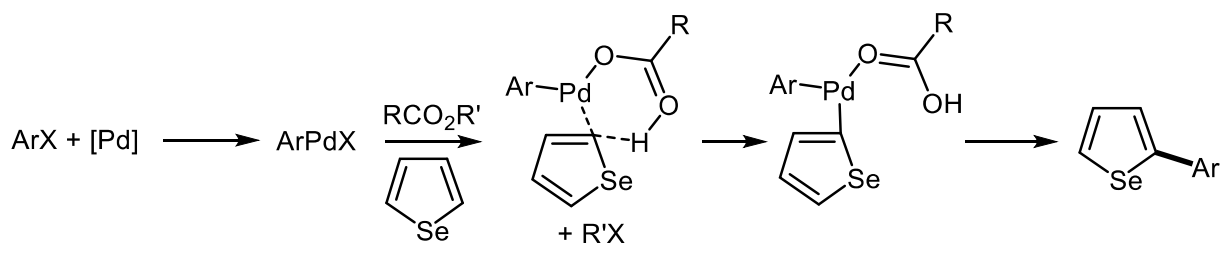

Scheme 20

The Pd-catalysed direct 2,5-diheteroarylation of 2,5-dibromoselenophene has been reported by Wipf et al. in 2014 (Scheme 21). ${ }^{[4]}$ Using ethyl oxazole-4-carboxylate as reaction partner, the corresponding 2,5-bis(oxazol-2-yl)selenophene derivative was formed in 45\% yield.

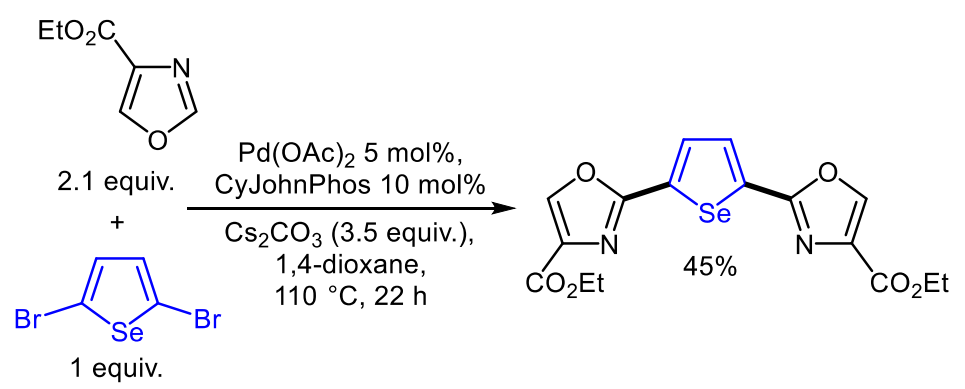

Scheme 21

It should also be mentioned that a few examples of $\mathrm{Rh}$ (III)-catalysed oxidative coupling of selenophene with a 2-phenylpyridine or with a 1-(pyrimidin-2-yl)-indole have been reported by Kambe et al. ${ }^{[50 \text {. }}$ These couplings, involved two $\mathrm{C}-\mathrm{H}$ bond cleavages and required 2.8-3.2 equiv. of $\mathrm{Cu}(\mathrm{OAc})_{2}$ as oxidant.

Whilst only a few examples of Pd-catalysed C2-arylations via the $\mathrm{C}-\mathrm{H}$ bond activation of selenophenes have been reported to date, there is no doubts that this methodology will facilitate the access to a variety of 2-(hetero)arylselenophenes or 2,5-di(hetero)arylselenophenes as there is no need to prepare an organometallic or a boron derivative. Both electron-poor and electron-rich aryl halides can be employed, and the reaction proceeds with easily available catalyst and base. The Pd-catalysed direct arylation using 2,5-dibromoselenophenes and heteroarenes for access to selenophenes bearing heteroarenes has also been described. Determining in more details the influence of (hetero)aryl halide coupling partners and also of selenophene substituents on such couplings is desirable and would certainly allow to replace in several cases Stille, Negishi or Suzuki couplings.

\section{C3-arylation of selenophenes}


The access to selenophenes derivatives bearing a functional group at C3-position which can be employed in palladium-catalysed cross-coupling reactions is quite challenging. The reaction of selenophene with bromine affords a mixture of poly(bromo)selenophenes. Then, the addition of acetic acid and zinc dust to the reaction mixture promotes the selective debromination at $\mathrm{C} 2$ and $\mathrm{C} 5$ positions affording 3-bromoselenophene in 47\% yield (Fig. 2, top). ${ }^{[51 \mathrm{a}]}$ 3,4-Dibromoselenophene can be prepared by treatment of tetrabromoselenophene by BuLi followed by hydrolysis (Fig. 2, middle). ${ }^{[51 b]}$ A 2,5diphenyl-substituted 3,4-dibromoselenophene has been prepared by reaction of 2,5-diphenylselenophene with bromine (Fig. 2, middle). ${ }^{[31]}$ However, in most cases, 3-halo-substituted selenophenes are prepared via multi-step synthesis, such as the cyclization of an homopropargylselenide in the presence of iodine to produce 3-iodoselenophenes after oxidation (Fig. 2, bottom). ${ }^{[52]}$
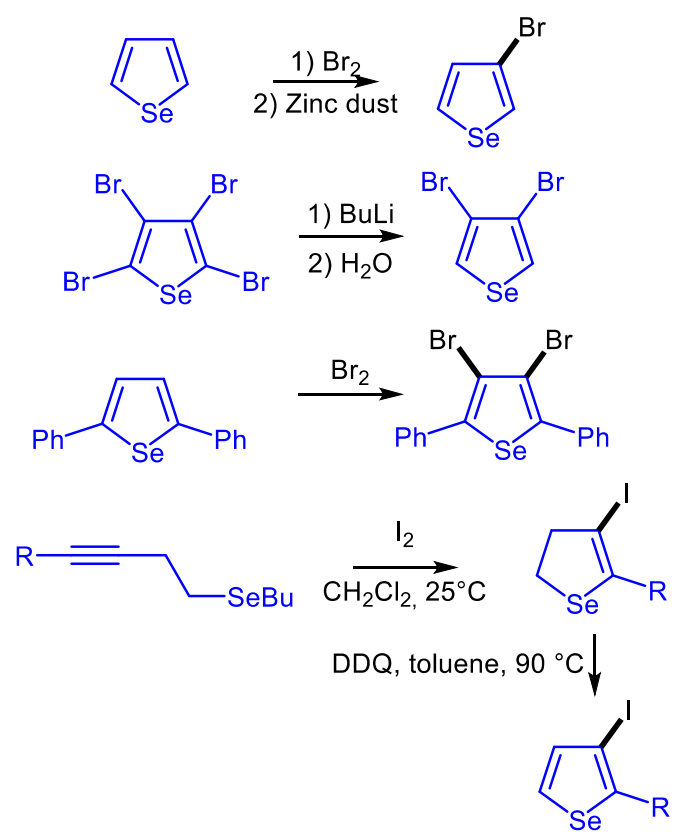

Figure 2

\subsection{C3-arylation via Stille coupling}

The preparation of 3-(trialkylstannyl)selenophene derivatives has not yet been reported. Even 3haloselenophenes have not been employed for the synthesis of C3-arylated selenophenes via Stille coupling; whereas a few examples of C3-arylations of benzoselenophenes, via Stille coupling, have been reported. In 2002, Deprets and Kirsch prepared 2-acetyl-3-phenylbenzoselenophene in high yield by reaction of a 3-bromobenzoselenophene with $\mathrm{PhSnBu}_{3}$ in the presence of $4 \mathrm{~mol} \% \mathrm{Pd}\left(\mathrm{PPh}_{3}\right)_{4}$ catalyst in dioxane (Scheme 22). ${ }^{[53]}$ 


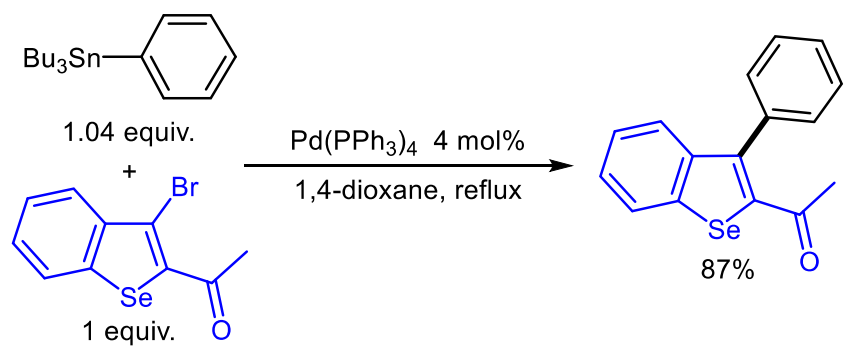

Scheme 22

Arsenyan group examined in 2011 the reactivity of a 3-bromobenzoselenophene with $\mathrm{HetArSnR}_{3}$ in the presence of $4 \mathrm{~mol} \% \mathrm{Pd}\left(\mathrm{PPh}_{3}\right)_{4}$ associated to $7 \mathrm{~mol} \% \mathrm{AsPh}_{3}$ in xylene (Scheme 23, top). ${ }^{[54]}$ This method allowed to introduce thienyl or pyridyl groups at C3-position of benzoselenophene. Then, in 2014 , Arsenyan et al. coupled 3,3'-dibromo-6,6'-bibenzo[b]selenophenes with 5-silyl-2trimethylstannylthiophenes containing chloropropyl and allyldimethylsilyl substituents, in order to synthesize $\pi$-conjugated systems (Scheme 23, middle). ${ }^{[55]}$ This Stille reaction proceeded in good yields using $20 \mathrm{~mol} \% \mathrm{Pd}\left(\mathrm{PPh}_{3}\right)_{4}$ associated to $\mathrm{AsPh}_{3}$ at $120{ }^{\circ} \mathrm{C}$. One year later, they extended their procedure to the coupling of a dibromoselenophenothiophene with 5-methylthien-2-yltributyltin (Scheme 23, bottom). ${ }^{[55 \mathrm{~b}]}$ Both thienyl and selenyl $\mathrm{C}-\mathrm{Br}$ bonds were reactive and the desired coupling product was obtained in almost quantitative yield. 


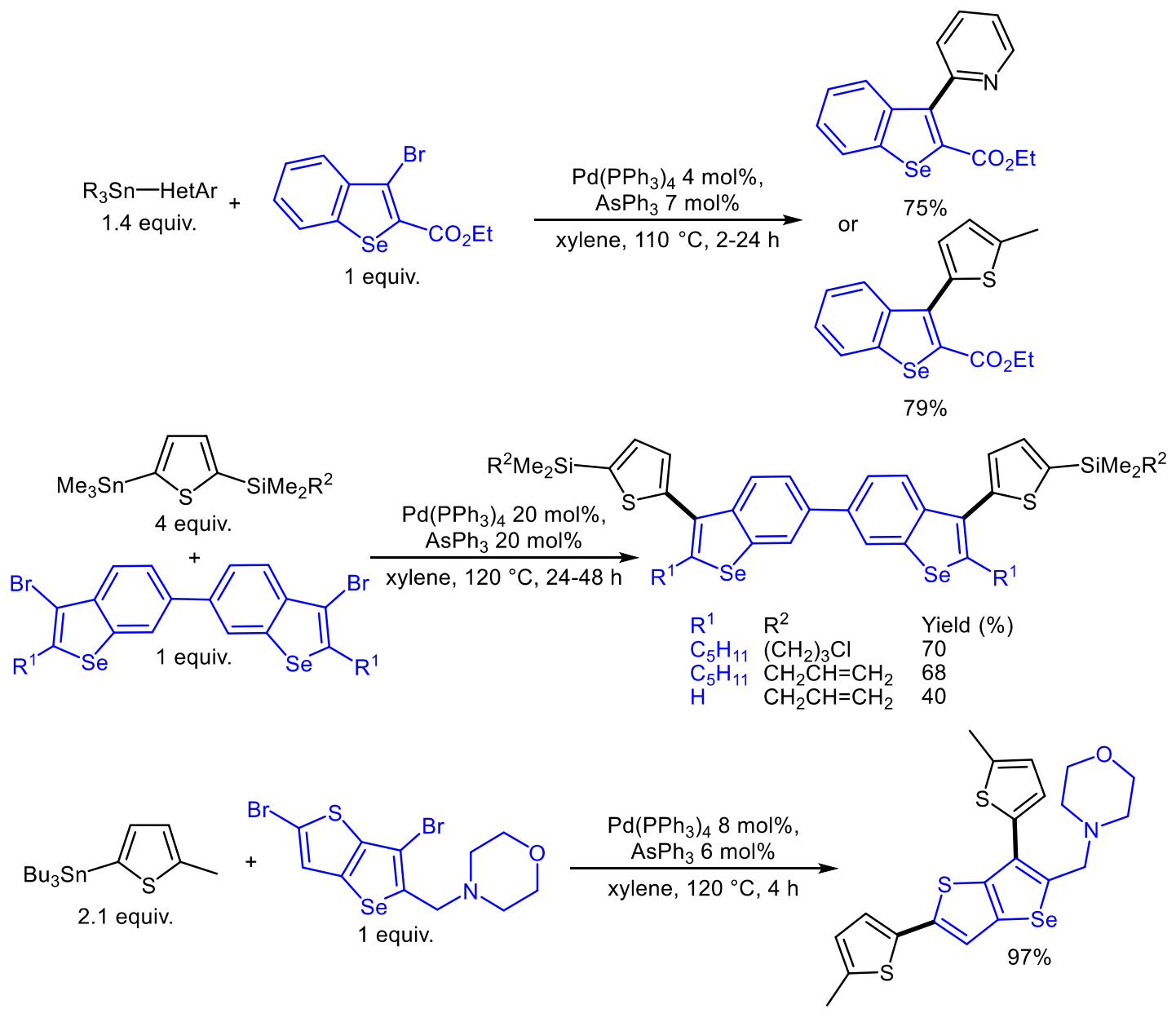

Scheme 23

In summary, the C3-arylation of selenophenes via Stille coupling has not been reported; whereas, 3bromobenzoselenophenes and analogues have been employed for the access to 3arylbenzoselenophenes.

\subsection{C3-arylation via Negishi coupling}

The first examples of C3-arylations of 3-haloselenophene derivatives via Negishi coupling were reported in 2008 by Zeni et al. (Scheme 24, top). ${ }^{[56 a]}$ From 1 equiv. of 2,5-disubstituted 3iodoselenophenes and 3 equiv. of organozinc compounds in the presence of $1 \mathrm{~mol} \% \mathrm{Pd}\left(\mathrm{PPh}_{3}\right)_{4}$ in THF, the C3-arylated selenophenes were obtained in moderate to high yields using both electron-rich and electron-poor arylzinc chlorides. Zeni et al. also arylated a 4-iodoselenophene[2,3-b]thiophene derivative with $p$-tolylzinc chloride under quite similar reaction conditions (Scheme 24 , bottom). ${ }^{56 \mathrm{~b}]}$ It should be mentioned that these couplings were performed at room temperature. 

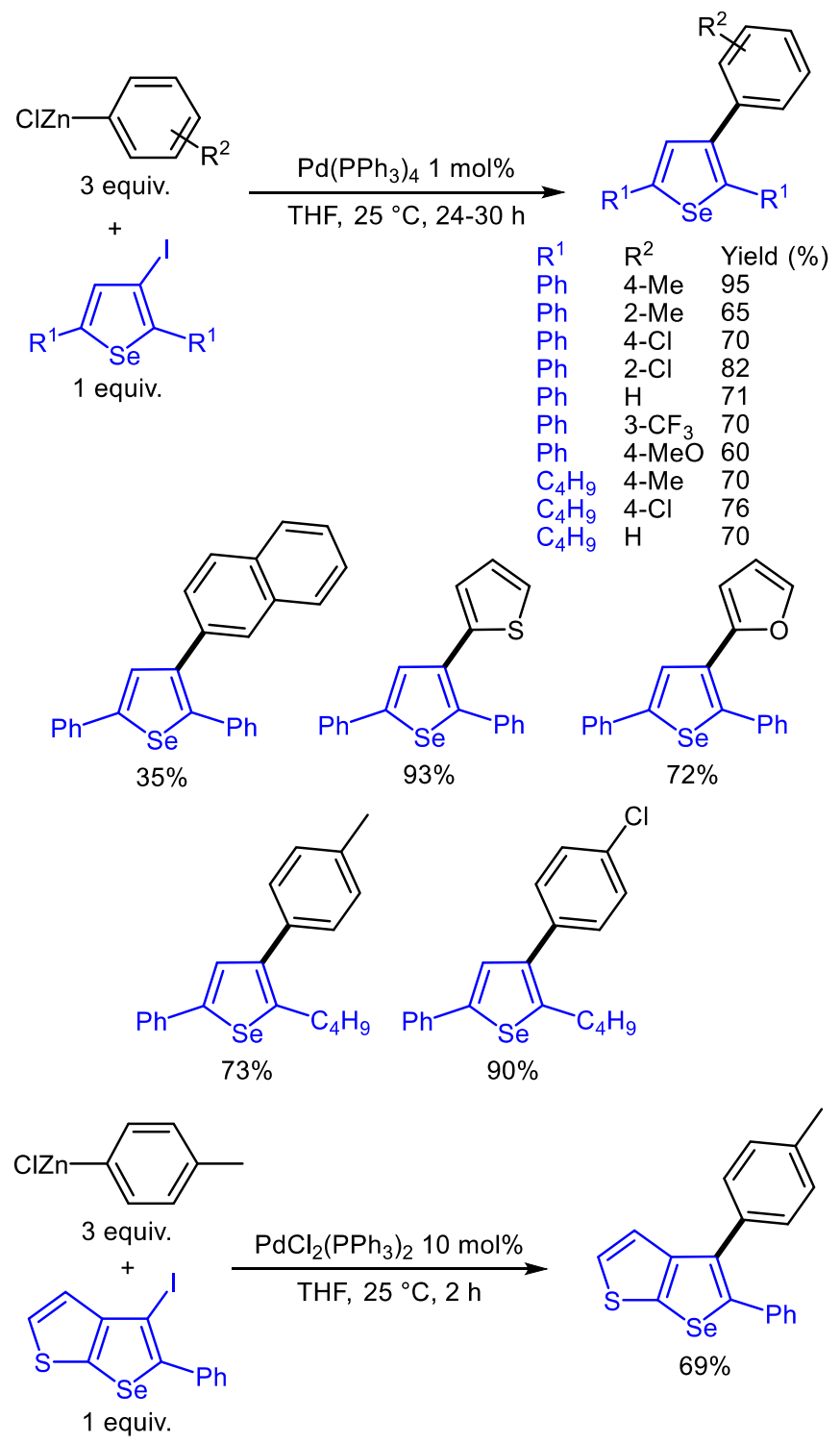

Scheme 24

\subsection{C3-arylation via Suzuki coupling}

As the synthesis of 3-selenopheneboronic acid derivatives in good yields remains difficult (so far, it has only been prepared by protodeboronation of 2,3,4,5-tetrakis(pinacolato)selenophene), ${ }^{[10]}$ for the synthesis of C3-arylated selenophenes via Suzuki coupling, in most cases 3-haloselenophenes were reacted with arylboronic acids. However, the first example of C3-arylation of selenophene via Suzuki coupling, which was reported in 1986, employed 3-selenopheneboronic acid as selenophenyl source (Scheme 25). ${ }^{[40]}$ Its reaction with 5-bromopyrimidines using $\mathrm{Pd}\left(\mathrm{PPh}_{3}\right)_{4}$ as catalyst afforded the 3heteroarylated selenophenes in $57-64 \%$ yields. 
30

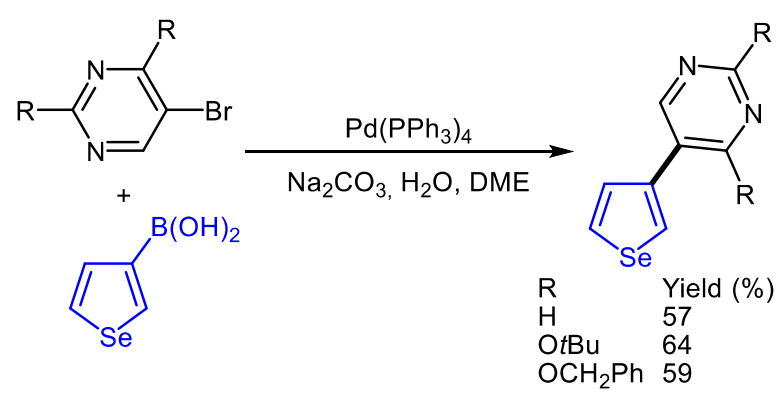

Scheme 25

Then, in 2001 an example of C3-arylation of a benzoselenophene via Suzuki coupling was reported by Deprets and Kirsch (Scheme 26). ${ }^{[57]}$ The use of $3 \mathrm{~mol} \% \mathrm{Pd}\left(\mathrm{PPh}_{3}\right)_{4}$ was found to promote very efficiently the coupling of a 2-formyl-3-bromobenzoselenophene with 2-(methylthio)phenylboronic acid, and the expected product was obtained in $79 \%$ yield. One year later, they extended this coupling procedure to the reaction of 2-acetyl-3-bromobenzoselenophene with benzeneboronic acid. ${ }^{[53]}$

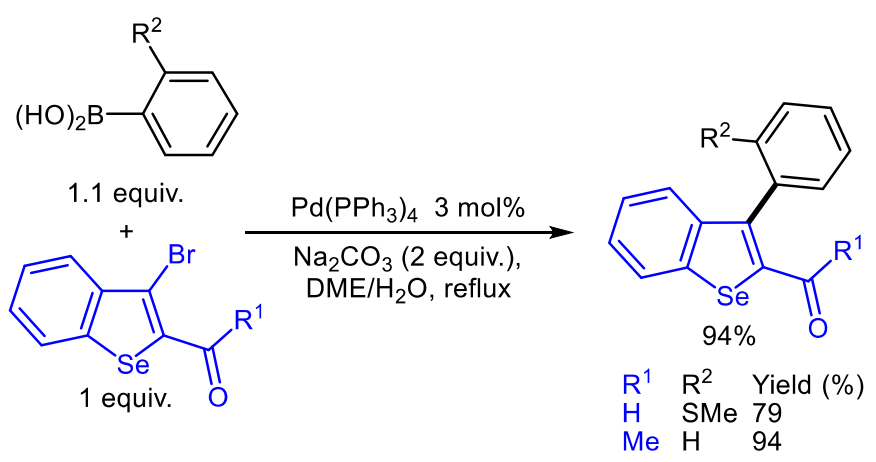

Scheme 26

A relatively similar procedure was employed in 2006 by Larock et al. for the C3-arylation of a 3iodobenzoselenophene (Scheme 27, top). ${ }^{[58]}$ Again, $\mathrm{Pd}\left(\mathrm{PPh}_{3}\right)_{4}$ was used as the catalyst, but $\mathrm{K}_{2} \mathrm{CO}_{3}$ was used as base instead of $\mathrm{Na}_{2} \mathrm{CO}_{3}$, and a mixture of DMF and water was employed as the solvent. Arsenyan group also examined the reactivity of a 2-substituted 3-bromobenzoselenophene in the presence of (hetero)arylboronic acids (Scheme 27, middle). They employed $10 \mathrm{~mol} \% \mathrm{Pd}(\mathrm{OAc})_{2}$ associated to $20 \mathrm{~mol} \% \mathrm{P}(o \text {-tol })_{3}$ as catalyst and $\mathrm{K}_{3} \mathrm{PO}_{4}$ as base, and obtained the $\mathrm{C} 3$-arylated benzoselenophenes in good yields, including with two heteroarenes: a 2-pyridineboronic acid and a 3thiopheneboronic acid. ${ }^{[54]}$ In 2014 and 2016, they extended this procedure to fluoro-substituted benzoselenophenes (Scheme 27, bottom). ${ }^{[59]}$ 

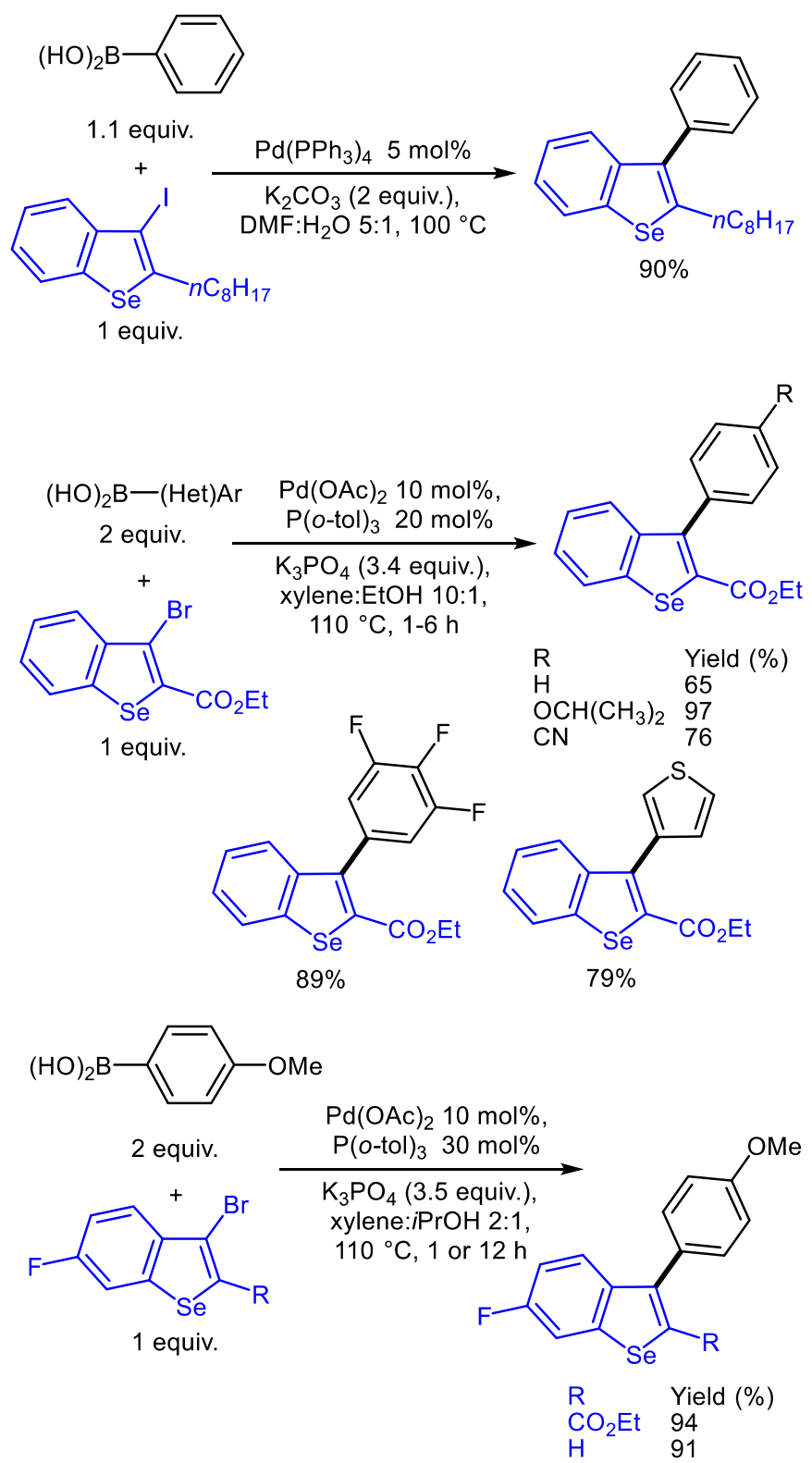

Scheme 27

Zeni et al. reported in 2008 conditions allowing the coupling of a wide variety of arylboronic acids with 2,5-disubstituted 3-iodoselenophenes (Scheme 28, top). ${ }^{[60]}$ In the presence of $5 \mathrm{~mol} \% \mathrm{Pd}(\mathrm{OAc})_{2}$ catalyst, arylboronic acids bearing electron-withdrawing or electron-donating substituents were tolerated affording the desired products in high yields. 3-Iodoselenophenes containing alkyl or hydroxyalkyl groups at C2- or C5-positions were successfully employed. Zeni et al. also prepared polyarylated selenophenes by reaction of 3-bromo-2,5-diphenylselenophenes or 3-bromo-2-phenylselenopnene with arylboronic acid derivatives (Scheme 28, middle). For these reactions, they employed $5 \mathrm{~mol} \%$ 
$\operatorname{Pd}\left(\mathrm{PPh}_{3}\right)_{4}$ as the catalyst. ${ }^{[61]}$ In 2015 , Zeni used a lower catalyst loading (2 mol\%) for the coupling of 2-benzoyl-4-iodo-5-phenylselenophene with 4-methoxybenzeneboronic acid (Scheme 28, bottom). ${ }^{\text {62] }}$

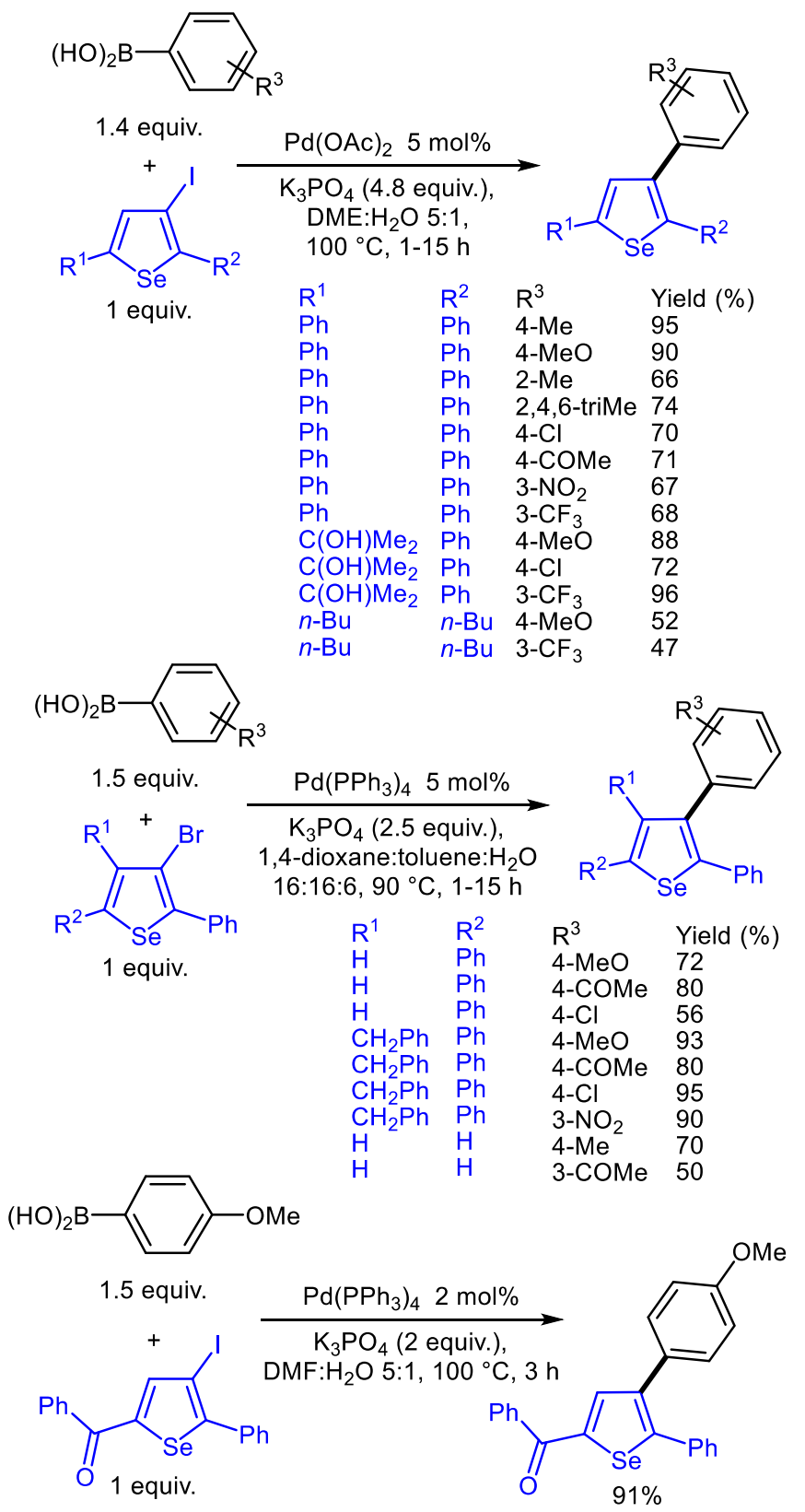

Scheme 28

Zeni's group also investigated the reactivity of a 4-iodoselenophene[2,3-b]thiophene in Suzuki coupling using 4-bromobenzeneboronic acid as aryl source (Scheme 29, top). Again, the expected coupling product was formed in good yield. Moreover, no cleavage of the arylboronic acid $\mathrm{C}-\mathrm{Br}$ bond was observed. ${ }^{[56 b]}$ Under the same reaction conditions, a 3-iodo-4H-selenopheno[3,2-c]chromene was arylated by $p$-tolylboronic acid at C3-position in high yield (Scheme 29 , bottom). ${ }^{[63]}$ 

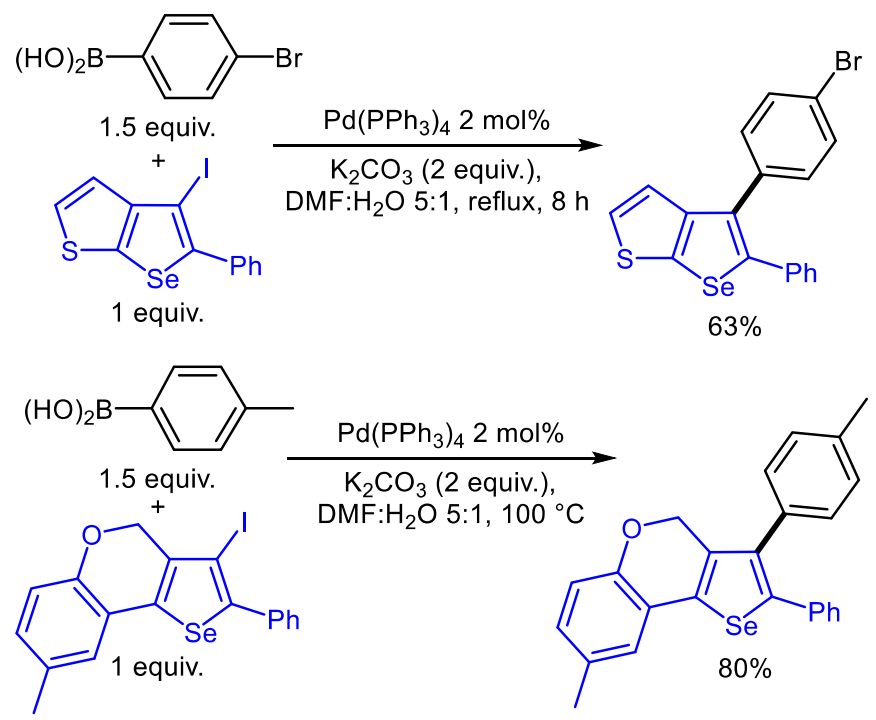

Scheme 29

In 2008, Langer et al. prepared a variety of 2,3,4,5-tetraarylselenophenes containing four identical aryl groups via Suzuki coupling, from 2,3,4,5-tetrabromoselenophene and arylboronic acids (Scheme 30, top). ${ }^{[33]}$ They also studied the reactivity of symmetrical 2,5-diaryl-3,4-dibromoselenophenes for access to 2,3,4,5-tetraarylselenophenes containing different aryl groups (Scheme 30, middle). Reaction with 4methoxybenzeneboronic acid gave the target products in $79 \%$ and $82 \%$ yields. A 3,4-dibromo-2,5dialkynylselenophene was also successfully employed affording the corresponding 3,4-diarylated 2,5dialkynylselenophene in 95\% yield (Scheme 30, middle). ${ }^{[64]}$ A similar procedure was employed by Haley et al. for the preparation of a diindenoselenophene in three steps. From 3,4-dibromoselenophene and a (dioxaborolan-2-yl)benzoate, using $\mathrm{Pd}_{2}(\mathrm{dba})_{3}$ associated to SPhos ligand as catalytic system, the corresponding 2,2'-(selenophene-3,4-diyl)dibenzoate was formed in 57\% yield (Scheme 30, bottom). ${ }^{[65]}$ 

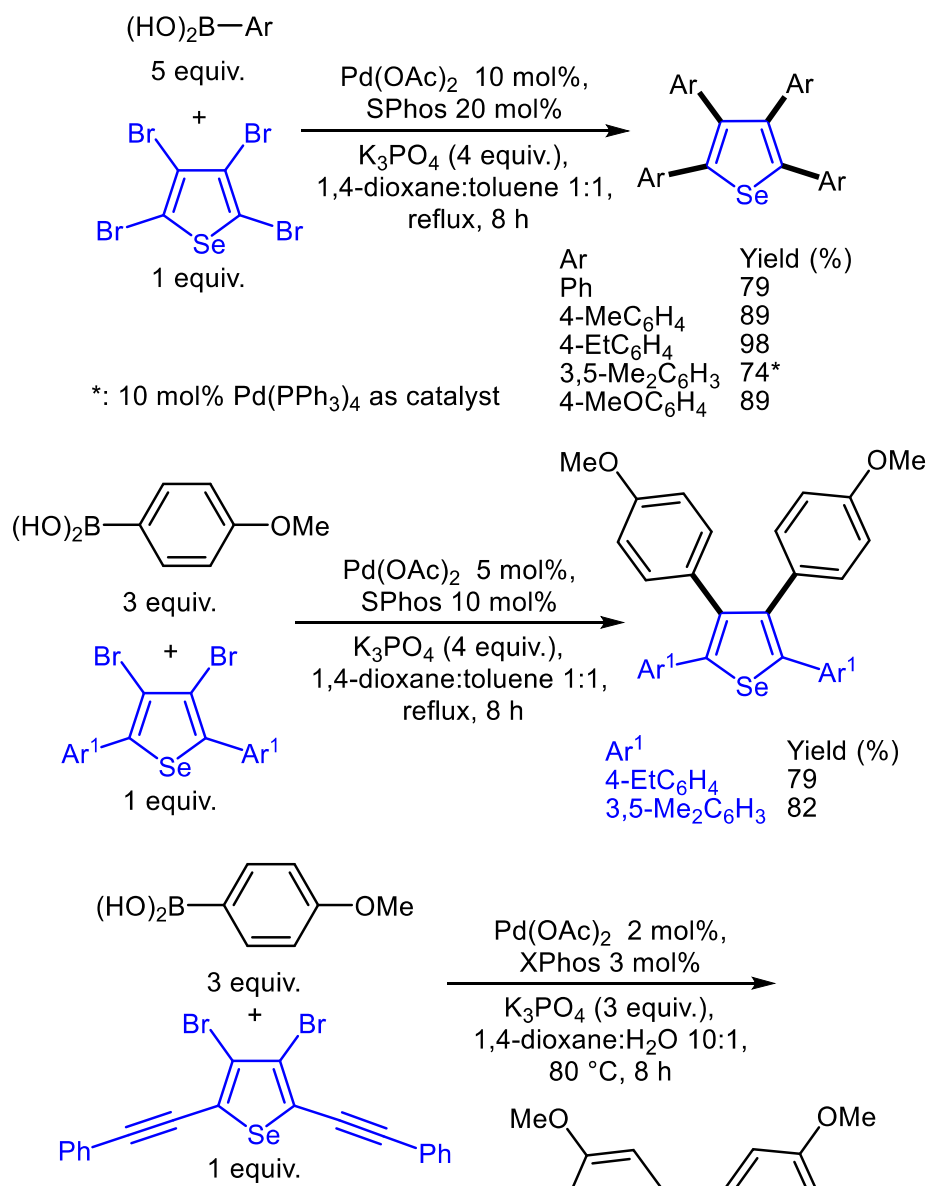

$\mathrm{Pd}(\mathrm{OAc})_{2} 2 \mathrm{~mol} \%$,

XPhos $3 \mathrm{~mol} \%$

1,4-dioxane: $\mathrm{H}_{2} \mathrm{O}$ 10:1, $80^{\circ} \mathrm{C}, 8 \mathrm{~h}$

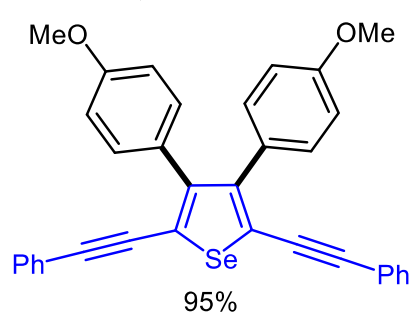<smiles>CCOC(=O)c1ccccc1B1OC2(C)CC2(C)O1</smiles>

$95 \%$

2.5 equiv.<smiles>Brc1c[se]cc1Br</smiles>

1 equiv.

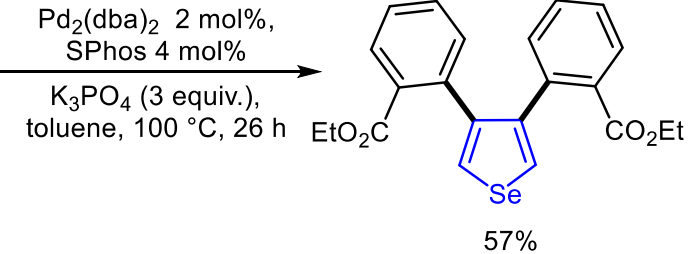

SPhos : 2-dicyclohexylphosphino-2',6'-dimethoxybiphenyl

XPhos : 2-dicyclohexylphosphino-2', 4', $^{\prime}$ '-triisopropylbiphenyl

Scheme 30

In summary, Suzuki coupling represents a very efficient method for the preparation of 3arylselenophenes. In most cases 3-bromo-, 3-iodo- or 3,4-dibromo-selenophenes, which are generally prepared via multi-steps synthesis, were employed as selenophenyl source and arylboronic acids as aryl 
source; whereas, 3-selenopheneboronic acids have been very rarely employed. This is certainly due to a limited access to such boron-containing selenophene derivatives.

\subsection{C3-arylation via C-H bond functionalization}

The first example of $\mathrm{Pd}$-catalysed direct arylation via $\mathrm{C}-\mathrm{H}$ bond activation at $\mathrm{C} 3$-position of selenophene was reported very recently by Ben Salem, Soulé, Doucet et al. (Scheme 31). ${ }^{[66 a]}$ They found that the Pdcatalysed coupling of benzenesulfonyl chlorides with selenophenes affords regiospecifically the C3arylated selenophenes. The reaction proceeds with easily accessible phosphine-free $\mathrm{Pd}(\mathrm{OAc})_{2}$ catalys 1 and $\mathrm{Li}_{2} \mathrm{CO}_{3}$ as base. Moreover, it tolerates a variety of substituents both on the benzene and selenophene moieties including bromo and iodo substituents (Scheme 31). It should be mentioned that the Pd-catalysed direct arylation of thiophenes with benzenesulfonyl chlorides also occurred at C3position; ${ }^{[66 \mathrm{~b}]}$ whereas, under the same reaction conditions, furans and pyrroles were arylated at $\mathrm{C} 2$ position. ${ }^{[66 c, d]}$
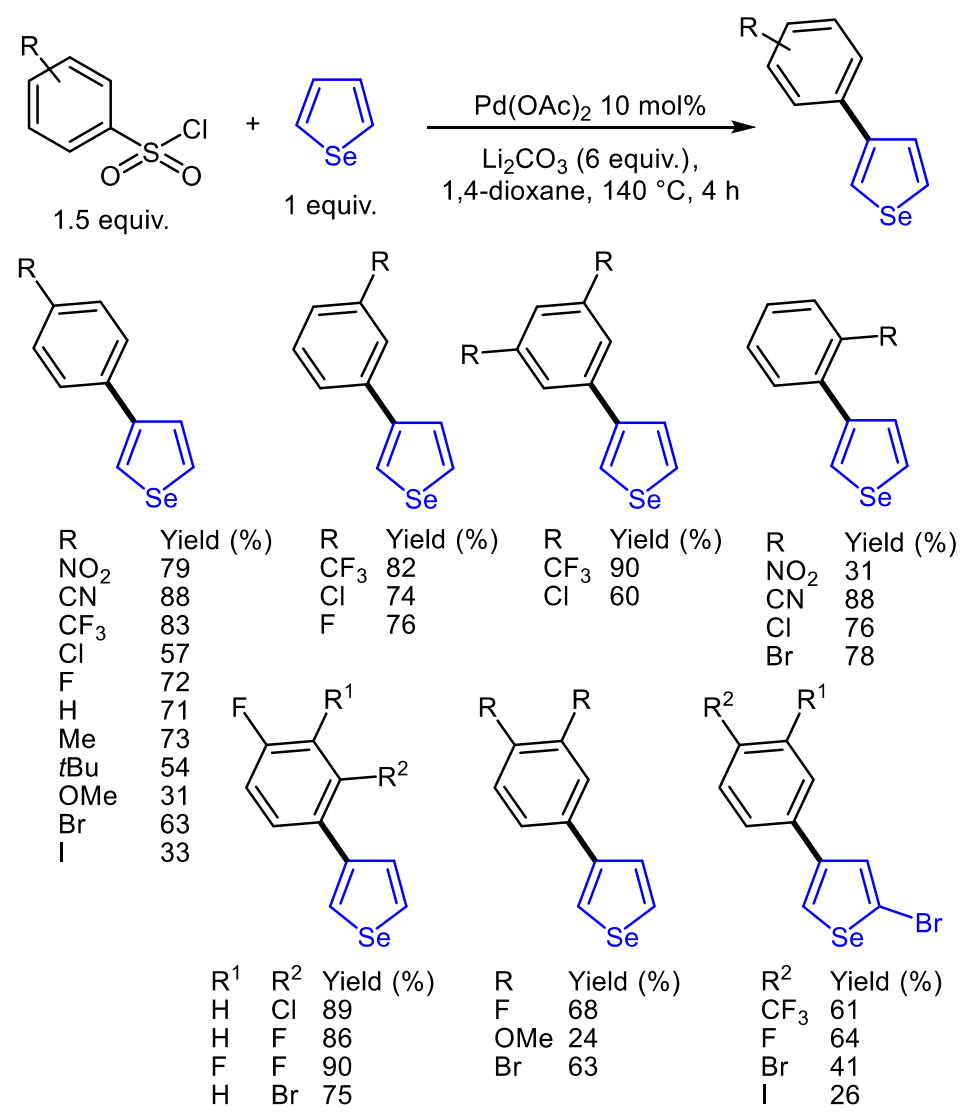

Scheme 31 
Under the same reaction conditions, the reaction of 3-(4-methoxyphenyl)selenophene with 4nitrobenzenesulfonyl chloride regioselectively affords the corresponding 3,4-diarylselenophene, which contains two different aryl groups, in $62 \%$ yield (Scheme 32, top). It was also possible to directly prepare by this method a 3,4-diarylselenophene bearing two identical aryl groups by reaction of selenophene with 3 equiv. of a benzenesulfonyl chloride derivative (Scheme 32, bottom).

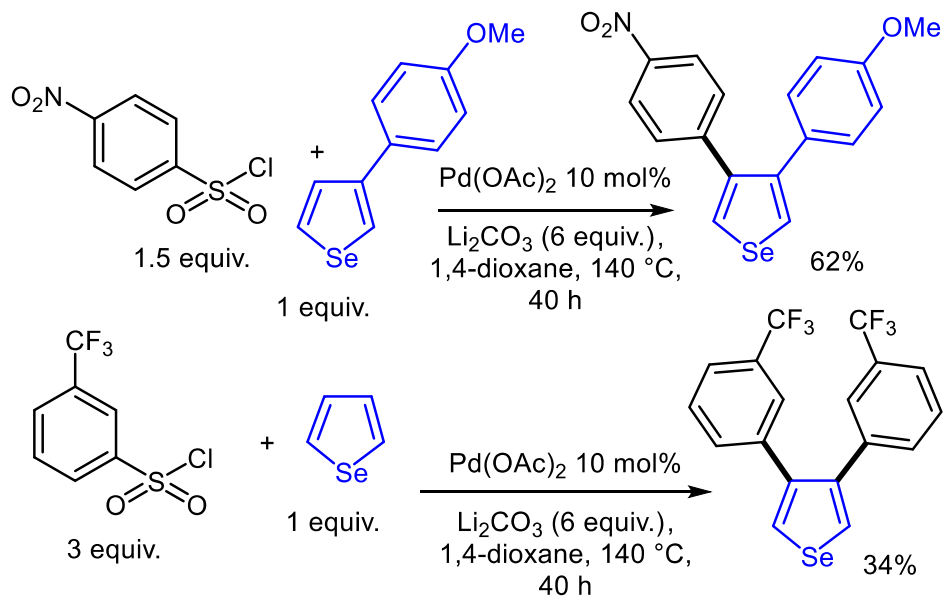

Scheme 32

A catalytic cycle was proposed for such Pd-catalysed direct C3-arylation of selenophenes using benzenesulfonyl chlorides as aryl source (Scheme 33). ${ }^{[66]}$ The first step would be the oxidative addition of the benzenesulfonyl chloride to $\mathrm{Pd}(\mathrm{II})$ to afford the $\mathrm{Pd}(\mathrm{IV})$ intermediate $\mathbf{A}$. Then, after elimination of $\mathrm{SO}_{2}$, the coordination of selenophene affords B., which gives $\mathbf{C}$ after migration of the aryl group to the $\beta$-carbon atom of selenophene. Finally, proton abstraction assisted by the base gives the $\beta$-arylated selenophene with the regeneration of the $\operatorname{Pd}(\mathrm{II})$ species.

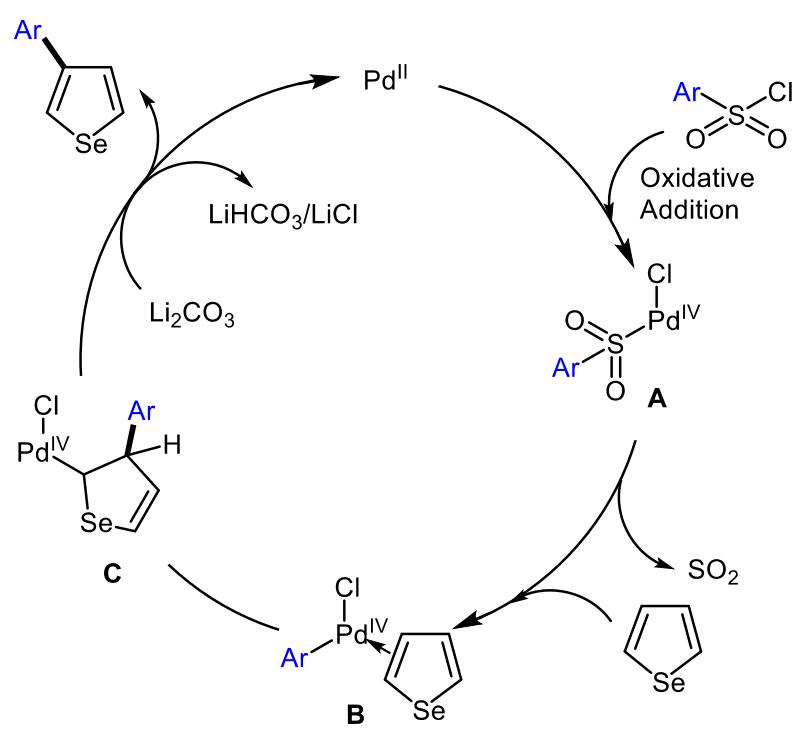


Scheme 33

The programmed synthesis of polyarylated selenophenes via successive Pd-catalysed C-H bond functionalisation reactions is possible, as the installation of aryl groups at the desired positions can be achieved (Scheme 34). ${ }^{[66]}$ From a 2,4-diarylselenophene (which was prepared by reaction of selenophene with 4-bromoacetophenone, followed by reaction with 4-(trifluoromethyl)benzenesulfonyl chloride) and 4-bromochlorobenzene in the presence of $2 \mathrm{~mol} \% \mathrm{Pd}(\mathrm{OAc})_{2}$ catalyst, a 2,3,5triarylselenophene containing three different aryl groups was obtained in $82 \%$ yield (Scheme 34 , top). A tetraarylated selenophene could be obtained by reaction of a 3,4-diarylselenophene (see scheme 31 , top) with 3 equiv. of 4-bromobenzonitrile in the presence of $\mathrm{Pd}(\mathrm{OAc})_{2}$ catalyst (Scheme 34, bottom).
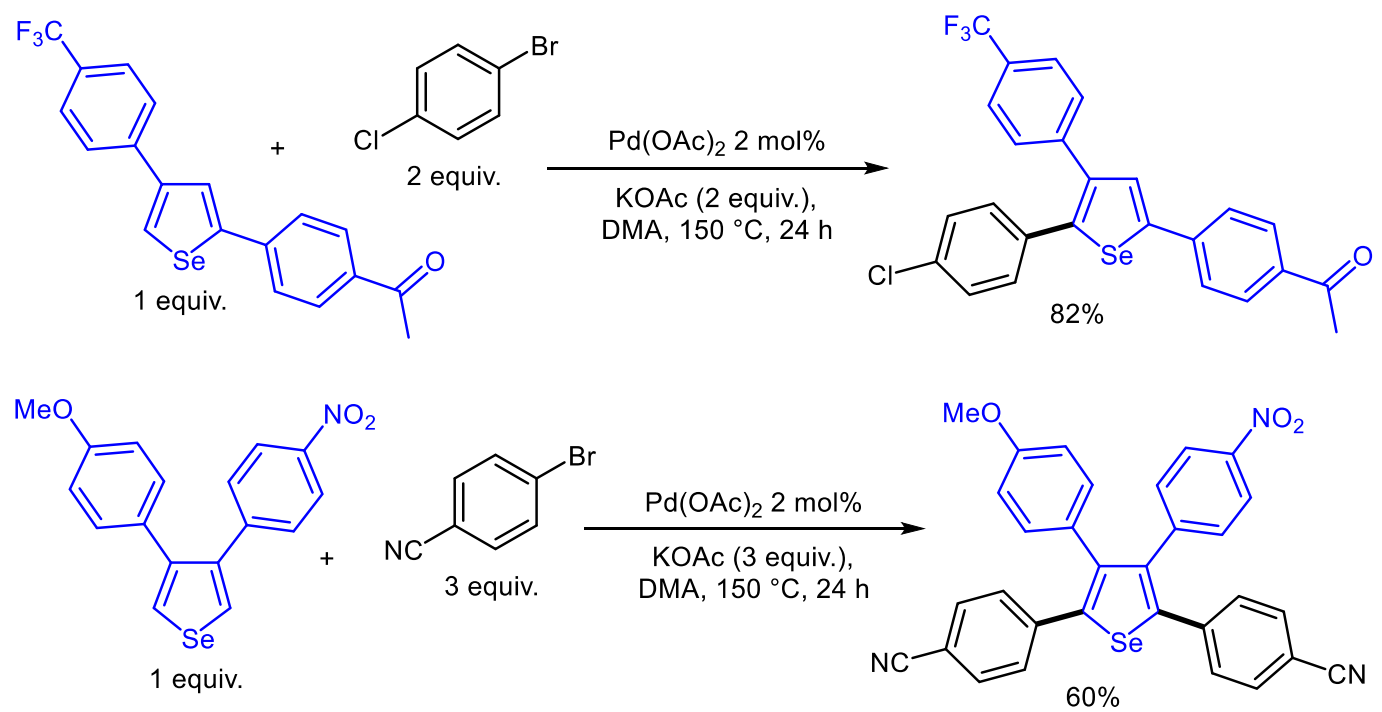

Scheme 34

In summary, the Pd-catalysed direct arylation at $\beta$-position of selenophene derivatives proceeds nicely with easily accessible phosphine-free $\mathrm{Pd}(\mathrm{OAc})_{2}$ catalyst and $\mathrm{Li}_{2} \mathrm{CO}_{3}$ as base and tolerates a wide variety of substituents both on the benzenesulfonyl chloride and selenophene coupling partners. Moreover, because of the possible installation of aryl groups at desired positions, this procedure allows the programmed synthesis of polyarylated selenophenes. Due to the wide availability of diversely functionalised benzenesulfonyl chlorides, this strategy (no expensive base and ligand) is very attractive to prepare $\beta$-arylated and polyarylated selenophenes.

\section{Conclusions and perspectives}


During the last two decades, the knowledge concerning the Pd-catalysed arylation of selenophenes has been widely extended. The various methods permitting to prepare the appropriate starting materials for specific cross-couplings, now allow to arylate regioselectively the different positions of selenophene. Initially, Stille coupling was the most employed route for the preparation of 2arylated selenophenes; however, for the last decade, Suzuki coupling represents the most commonly used methodology to prepare such compounds. Even if the C2-arylation of selenophenes remains generally simpler than their C3-arylation, due to an easier access to 2-haloselenophenes, several Negishi or Suzuki couplings for the preparation of 3-arylselenophenes have been reported. For both C2- and C3arylations of selenophenes via Stille, Negishi or Suzuki couplings, aryl iodides or aryl bromides were employed as the coupling partners; whereas, aryl chlorides have never been used.

Since 2011, the Pd-catalysed direct C2- or C3-arylation of selenophenes, via a C-H bond activation of selenophenes, has emerged as a very powerful alternative method. C-H bond functionalisation reaction for the introduction of aryl groups on selenophenes is very attractive, as no prior preparation of an organometallic derivative is required, reducing the number of steps to prepare the target compounds and as there is no need to functionalise the selenophene unit. For Pd-catalysed direct C2-arylations of selenophenes, aryl iodides and aryl bromides were employed as aryl source; whereas, direct C3-arylations of selenophenes were performed using benzenesulfonyl chlorides.

Even if a wide variety of (hetero)arylated selenophenes derivatives can be obtained via palladium-coupling reactions, many challenges remain, as the access to the some 3-halo- and especially 3-metal (or boron)-substituted selenophenes is problematic. In the near future, the Pd-catalysed direct arylation will certainly drastically modify the synthetic pathways for the preparation of arylated selenophenes, as it permits the programmed synthesis of polyarylselenophenes by the simple change of the aryl source. Determining in more details the mechanistic reasons of the various regioselectivities observed in Pd-catalysed direct arylation would certainly allow further improvements in terms of efficiency, mildness and reaction scope.

\section{References}

[1] a) J. Hollinger, A. A. Jahnke, N. Coombs, D. S. Seferos, J. Am. Chem. Soc. 2010, 132, 85468547; b) Y.-S. Yen, C.-T. Lee, C.-Y. Hsu, H.-H. Chou, Y.-C. Chen, J. T. Lin, Chem. Asian J. 2013, 8, 809-816.; c) Y. Liu, Y. Yang, C.-C. Chen, Q. Chen, L. Dou, Z. Hong, G. Li, Y. Yang, Adv. Mater. 2013, 25, 4657-4662; d) S. T. J. Ryan, R. M. Young, J. J. Henkelis, N. Hafezi, N. 
A. Vermeulen, A. Hennig, E. J. Dale, Y. Wu, M. D. Krzyaniak, A. Fox, W. M. Nau, M. R. Wasielewski, J. F. Stoddart, O. A. Scherman, J. Am. Chem. Soc. 2015, 137, 15299-15307.

[2] a) C. R. B. Rhoden, G. Zeni, Org. Biomol. Chem. 2011, 9, 1301-1313; b) H. Sashida, Yakugaku Zasshi 2016, 841-871.

[3] a) L. Ackermann, R. Vicente, A. R. Kapdi, Angew. Chem. Int. Ed. 2009, 48, 9792-9826; b) B.-J. Li, S.-D. Yang, Z.-J. Shi, Synlett 2008, 949-957; c) F. Kakiuchi, T. Kochi, Synthesis 2008, 3013-3039; d) G. P. McGlacken, L. M. Bateman, Chem. Soc. Rev. 2009, 38, 2447-2464; e) X. Chen, K. M. Engle, D.-H. Wang, J.-Q. Yu, Angew. Chem. Int. Ed. 2009, 48, 5094-5115; f) F. Bellina, R. Rossi, Tetrahedron 2009, 65, 10269-10310; g) T. Satoh, M. Miura, Synthesis 2010, 3395-3409; h) T. W. Lyons, M. S. Sanford, Chem. Rev. 2010, 110, 1147-1169; i) L. Ackermann, Chem. Rev. 2011, 111, 1315-1345; j) N. Kuhl, M. N. Hopkinson, J. WencelDelord, F. Glorius, Angew. Chem. Int. Ed. 2012, 51, 10236-10254; k) J. Wencel-Delord, F. Glorius, Nat. Chem. 2013, 5, 369-375; 1) M. He, J.-F. Soulé, H. Doucet, ChemCatChem 2014. 6, 1824-1859; m) R. Rossi, F. Bellina, M. Lessi, C. Manzini, Adv. Synth. Catal. 2014, 356, $17-$ 117; n) K. Yuan, J.-F. Soulé, H. Doucet, ACS Catal. 2015, 5, 978-991; o) M. R. Yadav, R. K. Rit, M. Shankar, A. K. Sahoo, Asian J. Org. Chem., 2015, 4, 846-864; p) L. Theveau, C. Schneider, C. Fruit, C. Hoarau, ChemCatChem 2016, 8, 3183-3194; q) C. B. Bheeter, L. Chen, J.-F. Soulé, H. Doucet, Cat. Sci. Technol. 2016, 6, 2005-2049; r) R. Rossi, M. Lessi, C. Manzini, G. Marianetti, F. Bellina, Tetrahedron 2016, 72, 1795-1837.

[4] a) S. Gronowitz, D. Peters, Heterocycles 1990, 30, 645-658; b) D. N. Antonov, L. I. Belen'kii, S. Gronowitz, J. Heterocycl. Chem. 1995, 32, 53-55; c) G. Zeni, Tetrahedron Lett. 2005, 46, 2647-2651; d) S. Haid, A. Mishra, C. Uhrich, M. Pfeiffer, P. Bauerle, Chem. Mater. 2011, 23, 4435-4444.

[5] a) D. Peters, A. B. Hoernfeldt, S. Gronowitz, J. Het. Chem. 1990, 27, 2165-2173; b) M. G. Pawar, A. Nuthanakanti, S. G. Srivatsan, Bioconjugate Chem. 2013, 24, 1367-1377.

[6] H. Pang, P. J. Skabara, D. J. Crouch, W. Duffy, M. Heeney, I. McCulloch, S. J. Coles, P. N. Horton, M. B. Hursthouse, Macromolecules 2007, 40, 6585-6593.

[7] a) S. Handa, E. Miyazaki, K. Takimiya, Chem. Commun. 2009, 3919-3921; b) For similar Stille couplings see: J. Huang, H. Jia, L. Li, Z. Lu, W. Zhang, W. He, B. Jiang, A. Tang, Z. Tan, C. Zhan, Y. Li, J. Yao, Phys. Chem. Chem. Phys. 2012, 14, 14238-14242.

[8] V. Tamilavan, J. B. Park, I-N. Kang, D.-H. Hwang, M. H. Hyun, Synth. Met. 2014, 230-238. 
[9] See also: V. Agrawal, Shahjad, D. Bhardwaj, R. Bhargav, G. D. Sharma, R. K. Bhardwaj, A. Patra, S. Chand, Electrochim. Acta 2016, 192, 52-60.

[10] W. Torres Delgado, F. Shahin, M. J. Ferguson, R. McDonald, G. He, E. Rivard, Organometallics 2016, 35, 2140-2148.

[11] a) D. Khim, W.-H. Lee, K.-J. Baeg, D.-Y. Kim, I.-N. Kang, Y.-Y. Noh, J. Mater. Chem. 2012, 22, 12774-12783; b) see also: W.-H. Lee, S. K. Son, K. Kim, S. K. Lee, W. S. Shin, S.-J. Moon, I.-N. Kang, Macromolecules 2012, 45, 1303-1312; c) W.-H. Lee, S. K. Lee, S. K. Son, J.-E. Choi, W. S. Shin, K. Kim, S.-H. Lee, S.-J. Moon, I.-N. Kang, J. Polym. Sci. Pol. Chem. 2012, 50, 551-561.

[12] S. Haid, A. Mishra, M. Weil, C. Uhrich, M. Pfeiffer, P. Baeuerle, Adv. Funct. Mater. 2012, 22, $4322-4333$.

[13] C.-H. Tsai, A. Fortney, Y. Qiu, R. R Gil, D. Yaron, T. Kowalewski, K. J. T. Noonan, J. Am. Chem. Soc. 2016, 138, 6798-6804.

[14] a) G. A. Cetin, A. Balan, A. Durmus, G. Gunbas, L. Toppare, Org. Electron. 2009, 10, 34-41; b) B. Lu, S. ming, K. Lin, S. Zhen, H. Liu, H. Gu, S. Chen, Y. Li, Z. Zhu, J. Xu, New J. Chem. 2016, 40, 8316-8323.

[15] H.-Y. Chen, S.-C. Yeh, C.-T. Chen, C.-T. Chen, J. Mater. Chem. 2012, 22, 21549-21559.

[16] E. Poverenov, N. Zamoshchik, A. Patra, Y. Ridelman, M. Bendikov, J. Am. Chem. Soc. 2014. 136, 5138-5149.

[17] P. B. Pati, S. Das, S. S. Zade, J. Polym. Sci. Pol. Chem. 2012, 50, 3996-4003.

[18] a) Y. A. Udum, S. Tarkuc, L. Toppare, Synth. Met. 2009, 159, 361-365; b) See also for the synthesis of a very similar compound via this procedure: P. Data, M. Lapkowski, R. Motyka, J. Suwinski, Electrochim. Acta 2012, 83, 271-282.

[19] a) J. J. Intemann, K. Yao, H.-L. Yip, Y.-X. Xu, Y.-X. Li, P.-W. Liang, F.-Z. Ding, X. Li, A; K.Y. Jen, Chem. Mater. 2013, 25, 3188-3195; For the synthesis of this product via a slightly different procedure, see: H.-H. Chang, C.-E. Tsai, Y.-Y. Lai, W.-W. Liang, S.-L. Hsu, C.-S. Hsu, Y.-J. Cheng, Macromolecules 2013, 46, 7715-7726.

[20] J.-Y. Lee, S.-H. Kim, I.-S. Song, D.-K. Moon, J. Mater. Chem. 2011, 21, 16480-16487.

[21] R. Li, X. Lv, D. Shi, D. Zhou, Y. Cheng, G. Zhang, P. Wang, J. Phys. Chem. C 2009, 113, 7469-7479.

[22] P. B. Pati, S. S. Zade, Tetrahedron 2013, 69, 2167-2174.

[23] F. Gao, Y. Cheng, Q. Yu, S. Liu, D. Shi, Y. Li, P. Wang, Inorg. Chem. 2009, 48, 2664-2669. 
[24] a) P.-F. Li, C. Qian, A. J. Lough, G. A. Ozin, D. S. Seferos, Dalton Trans. 2016, 45, 97549757; b) D. P. Sweat, C. E. Stephens, Synthesis 2009, 3214-3218.

[25] R. Shabana, A. Galal, H. B. Mark Jr.; H. Zimmer, S. Gronowitz, A. B. Hoernfeldt, J. Chem. Soc., Chem. Commun. 1988, 988-999.

[26] K. Takahashi, A. Gunji, Heterocycles 1996, 43, 941-944.

[27] H. Ohishi, M. Tanaka, H. Kageyama, Y. Shirota, Chem. Lett. 2004, 33, 1266-1267.

[28] a) J. Nakayama, H. Dong, K. Sawada, A. Ishii, S. Kumakura, Tetrahedron 1996, 52, 471-488; b) H. Kong, Y. K. Jung, N. S. Cho, I.-N. Kang, J.-H. Park, S. Cho, H.-K. Shim, Chem. Mater. 2009, 21, 2650-2660; c) M. Verswyvel, J. Steverlynck, S. Hadj Mohamed, M. Trabelsi, B. Champagne, G. Koeckelberghs, Macromolecules 2014, 47, 4668-4675.

[29] a) K. Takimiya, N. Niihara, T. Otsubo, Synthesis 2005, 1589-1592; b) K. Takimiya, Y. Kunugi, H. Ebata, T. Otsubo, Chem. Lett. 2006, 35, 1200-1201.

[30] P. Prediger, A. V. Moro, C. W. Nogueira, L. Savegnago, P. H. Menezes, J. B. T. Rocha, G. Zeni, J. Org. Chem. 2006, 71, 3786-3792.

[31] T. Kimura, N. Murakami, Heteroat. Chem. 2014, 25, 428-433.

[32] a) E. Bey, S. Marchais-Oberwinkler, R. Werth, M. Negri, Y. A. Al-Soud, P. Kruchten, A. Oster, M. Frotscher, B. Birk, R. W. Hartmann, J. Med. Chem. 2008, 51, 6725-6739; b) D. Fujita, Y. Ueda, S. Sato, N. Mizuno, T. Kumasaka, M. Fujita, Nature 2016, 540, 563-566.

[33] D. T. Tung, A. Villinger, P. Langer, Adv. Synth. Catal. 2008, 350, 2109-2117.

[34] T. Klingstedt, H. Shirani, K. O. A. Aaslund, N. J. Cairns, C. J. Sigurdson, M. Goedert, K. P. R. Nilsson, Chem. Eur. J. 2013, 19, 10179-10192.

[35] See also: H. Shirani, M. Linares, C. J. Sigurdson, M. Lindgren, P. Norman, K. P. R. Nilsson, Chem. Eur. J. 2015, 21, 15133-15137.

[36] J. Salamoun, S. Anderson, J. C. Burnett, R. Gussio, P. Wipf, Org. Lett. 2014, 16, 2034-2037.

[37] P.-Y. Ho, C.-H. Siu, W.-H. Yu, P. Zhou, T. Chen, C.-L. Ho, L. T. L. Lee, Y.-H. Feng, J. Liu, K. Han, Y. H. Lo, W.-Y. Wong J. Mater. Chem. C 2016, 4, 713-726.

[38] a) H. Kong, D. S. Chung, I.-N. Kang, J.-H. Park, M.-J. Park, I. H. Jung, C. E. Park, H.-K. Shim, J. Mater. Chem. 2009, 19, 3490-3499; b) H. Kong, Y. K. Jung, N. S. Cho, I.-N. Kang, J.-H. Park, S. Cho, H.-K. Shim, Chem. Mater. 2009, 21, 2650-2660.

[39] S. P. Mishra, A. E. Javier, R. Zhang, J. Liu, J. A. Belot, I. Osaka, R. D. McCullough, J. Mater. Chem. 2011, 21, 1551-1561.

[40] S. Gronowitz, A. B. Hoernfeldt, V. Kristjansson, T. Musil, Chem. Scr. 1986, 26, 305-309. 
[41] P. Naus, R. Pohl, I. Votruba, P. Dzubak, M. Hajduch, R. Ameral, G. Birkus, T. Wang, A. S. Ray, R. Mackman, T. Cihlar, M. Hocek, J. Med. Chem. 2010, 53, 460-470.

[42] R. Shabana, A. Galal, H. B. Mark Jr., H. Zimmer, S. Gronowitz, A. B. Hoernfeldt, Phosphorus, Sulfur Silicon Relat. Elem. 1990, 48, 239-244.

[43] For a similar coupling see: M. J. Cho, J. Shin, S. H. Yoon, T. W. Lee, M. Kaur, D. H. Choi, Chem. Commun. 2013, 49, 7132-7134.

[44] A. Bedi, S. S. Zade, Macromolecules 2013, 46, 8864-8872.

[45] a) N. Nakamura, Y. Tajima, K. Sakai, Heterocycles 1982, 17, 235-245; b) A. Ohta, Y. Akita, T. Ohkuwa, M. Chiba, R. Fukunaga, A. Miyafuji, T. Nakata, N. Tani, Y. Aoyagi, Heterocycles 1990, 31, 1951-1958.

[46] S. Tamba, R. Fujii, A. Mori, K. Hara, N. Koumura, Chem. Lett. 2011, 40, 922-924.

[47] D. S. Rampon, L. A. Wessjohann, P. H. Schneider, J. Org. Chem. 2014, 79, 5987-5992.

[48] a) D. García-Cuadrado, A. A. C. Braga, F. Maseras, A. M. Echavarren, J. Am. Chem. Soc. 2006, 128, 1066-1067; b) S. I. Gorelsky, D. Lapointe, K. Fagnou, J. Am. Chem. Soc. 2008, 130, 10848-10849; c) Y. Boutaldla, D. L. Davies, S. A. Macgregor, A. I. Poblador-Bahamonde, Dalton Trans. 2009, 5820-5831; d) S. I. Gorelsky, Coord. Chem. Rev. 2013, 257, 153-164.

[49] J. Salamoun, S. Anderson, J. C. Burnett, R. Gussio, P. Wipf, Org. Lett. 2014, 16, 2034-2037.

[50] V. P. Reddy, R. Qiu, T. Iwasaki, N. Kambe, Org. Lett. 2013, 15, 1290-1293.

[51] a) A. Hallberg, S. Liljefors, P. Pedaja, Synth. Commun. 1981, 11, 25-28; b) A. Patra, Y. H. Wijsboom, G. Leitus, M. Bendikov, Chem. Mater. 2011, 23, 896-906.

[52] R. F. Schumacher, A. R. Rosario, A. C. G. Souza, P. H. Menezes, G. Zeni, Org. Lett. 2010, 12, 1952-1955.

[53] S. Deprets, G. B. Kirsch, Arkivoc 2002, 40-48.

[54] P. Arsenyan, E. Paegle, S. Belyakov, I. Shestakova, E. Jaschenko, I. Domracheva, J. Popelis, Eur. J. Med. Chem. 2011, 46, 3434-3443.

[55] a) P. Arsenyan, J. Vasiljeva, S. Belyakov, Mendeleev Commun. 2014, 24, 32-34; b) P. Arsenyan, A. Petrenko, S. Belyakov, Tetrahedron 2015, 71, 2226-2233.

[56] a) R. F. Schumacher, D. Alves, R. Brandao, C. W. Nogueira, G. Zeni, Tetrahedron Lett. 2008, 49, 538-542; b) A. L. Stein, J. da Rocha, P. H. Menezes, G. Zeni, Eur. J. Org. Chem. 2010, 705-710.

[57] S. Deprets, G. Kirsch, Heterocycl. Commun. 2001, 7, 421-426.

[58] T. Kesharwani, S. A. Worlikar, R. C. Larock, J. Org. Chem. 2006, 71, 2307-2312. 
[59] a) P. Arsenyan, E. Paegle, I. Domracheva, A. Gulbe, I. Kanepe-Lapsa, I. Shestakova, Eur. J. Med. Chem. 2014, 87, 471-483; b) E. Paegle, I. Domracheva, B. Turovska, M. Petrova, I. Kanepe-Lapsa, A. Gulbe, E. Liepinsh, P. Arsenyan, Chem. Asian J. 2016, 11, 1929-1938.

[60] D. A. Barancelli, D. Alves, P. Prediger, E. C. Stangherlin, C. W. Nogueira, G. Zeni, Synlett 2008, 119-125.

[61] a) D. A. Barancelli, R. F. Schumacher, M. R. Leite, G. Zeni, Eur. J. Org. Chem. 2011, 67136718 ; b) D. A. Barancelli, C. I. Acker, P. H. Menezes, G. Zeni, Org. Biomol. Chem. 2011, 9, 1529-1537; c) R. F. Schumacher, A. R. Rosario, M. R. Leite, G. Zeni, Chem. Eur. J. 2013, 19, 13059-13064.

[62] J. A. Roehrs, R. P. Pistoia, D. F. Back, G. Zeni, J. Org. Chem. 2015, 80, 12470-12481.

[63] A. Speranca, B. Godoi, M. D. Costa, P. H. Menezes, G. Zeni, Tetrahedron Lett. 2011, 52, 388391.

[64] P. Ehlers, T. T. Dang, T. Patonay, A. Villinger, P. Langer, Eur. J. Org. Chem. 2013, 20002007.

[65] J. L. Marshall, G. E. Rudebusch, C. L. Vonnegut, L. N. Zakharov, M. M. Haley, Tetrahedron Lett. 2015, 56, 3235-3239.

[66] a) A. Skhiri, R. Ben Salem, J.-F. Soulé, H. Doucet, Chem. Eur. J. 2017, 23, 2788-2791; For C3arylation of thiophenes: b) K. Yuan, H. Doucet, Chem. Sci. 2014, 5, 392-396; For C2-arylation of furans and pyrroles using benzenesulfonyl chlorides: c) A. Beladhria, K. Yuan, H. Ben Ammar, J.-F. Soulé, R. Ben Salem, H. Doucet, Synthesis 2014, 46, 2515-2523; d) R. Jin, K. Yuan, E. Chatelain, J.-F. Soulé, H. Doucet, Adv. Synth. Catal. 2014, 356, 3831-3841. 